\title{
Quantitative Validation of Carbon-Fiber Laminate Low Velocity Impact Simulations
}

\author{
Shawn A. English*, Timothy M. Briggs, Stacy M. Nelson \\ Sandia National Laboratories, Livermore, CA 94550, USA \\ *Corresponding author. Tel.: +00 1 9252946819,E-mail: saengli@sandia.gov
}

\begin{abstract}
Simulations of low velocity impact with a flat cylindrical indenter upon a carbon fiber fabric reinforced polymer laminate are rigorously validated. Comparison of the impact energy absorption between the model and experiment is used as the validation metric. Additionally, non-destructive evaluation, including ultrasonic scans and three-dimensional computed tomography, provide qualitative validation of the models. The simulations include delamination, matrix cracks and fiber breaks. An orthotropic damage and failure constitutive model, capable of predicting progressive damage and failure, is developed in conjunction and described. An ensemble of simulations incorporating model parameter uncertainties is used to predict a response distribution which is then compared to experimental output using appropriate statistical methods. Finally, the model form errors are exposed and corrected for use in an additional blind validation analysis. The result is a quantifiable confidence in material characterization and model physics when simulating low velocity impact in structures of interest.
\end{abstract}

\section{Keywords}

Carbon fiber; Delamination; Impact behavior; Finite element analysis; Statistical methods

\section{Introduction}

Fabric reinforced polymer laminates are used in a wide variety of structural applications. Numerical analysis of composite structures is critical for design and damage tolerance assessment. Laminates consisting of fabric reinforced lamina further complicate analysis methods because each ply cannot be idealized as a unidirectional layer, but is in reality a complex yarn structure with crimp and undulations. Therefore, a homogenized approach to lamina modeling is needed $[1,2]$ for woven fabric architectures. Additionally, laminates exhibit directional dependent strength, stiffness and toughness. Abnormal loads, such as transverse impact, can inflict considerable damage in components that significantly reduce the design envelope. For this reason, low velocity impact (LVI) is a commonly studied condition when assessing damage tolerance of composite laminates with relevancies spanning from defense applications to recreational products [3-21]. The likelihood of occurrence coupled with the potential for sub-surface, barely visible impact damage (BVID) that can significantly degrade a component make this 'old' problem still a rather pervasive issue to consider in engineering designs. There are a number of influential variables in the impact event that merit consideration when discussing the nature of the response and the anticipated damage mechanisms. Some of more relevant physical parameters that have been explored by researchers include projectile material, shape, mass and velocity [10-14], the target laminate boundary conditions [15, 16], stack sequence and fabric architecture [17], as well as the thickness [18].

One distinct limitation in most numerical studies to date is the lack of vetting through sampling the entire parameter space [9, 19-21]. With the advancement of high performance computing, large ensembles of simulations can be run with the goal of better quantifying the uncertainties inherent in model predictions. Furthermore, validation can only be achieved within some statistical space when the bounds of model uncertainty are fully explored. Validation, an essential element in the qualification of numerical models, is used to build quantifiable confidence in simulation results. The definition of validation is: "The process of determining the degree to which a computer model is an accurate representation of the real world from the perspective of the intended model applications" [22]. Each input of the model adds a degree of freedom making the isolation of the highly contributing inputs difficult. To remedy this, a sensitivity analysis is conducted prior to the implementation of a validation analysis.

While many post impact damage analysis techniques to evaluate damage tolerance rely on the compression after impact (CAI) experiment [9], this study will utilize a quasi-quantitative analysis of the impact delamination and damage [23] zone to assess the nature and extent of damage. Detailed insight of the impact-damaged zone is 
achieved through ultrasonic mapping [24]. Additionally, post-impact specimens are scanned and imaged using 3D computed tomography (CT) for even greater insight into the nature and extent of damage mechanisms.

This work documents a validation effort for the LVI modeling of carbon fiber reinforced composite. In the case of LVI with post-test non-destructive evaluation (NDE), quantitative as well as qualitative assessment is necessary. Where the residual strength is untested in both experiments and model, the qualitative metrics such as crack length and depth, delaminated area and quasi-quantitative metrics such as load time shape are an important way to assess relevant engineering statistics. However, a qualification metric must be quantifiable and contain sensitivities to many of the input parameters. Calibration, or the isolation and adjustment of model inputs in order to match the experimental response, is only completed to prove deficiencies in the model and direct future efforts. The primary metric for comparison is the change in kinetic energy calculated before and after the impact event using the initial and rebound velocities of the indenter fixture, respectively. The experiments are conducted on a 12 layer laminate constructed of an 8-harness satin weave carbon fiber reinforced polymer (CFRP). The material is minimally characterized, leaving many model inputs unknown. Additionally, the force time histories and pre- and post-impact ultrasonic scans are utilized as validation metrics. A project status report documents some preliminary aspects of this study in greater detail [25].

\section{Experiments}

\section{Materials and Apparatus}

The CFRP material used for this investigation consists of an 8-harness satin weave prepreg with an epoxy based resin. Laminates are hand layed up from precut ply kits. The material is cured in the form of flat plates using a standard autoclave process under vacuum at a temperature of $177 \mathrm{C}$ and a pressure of $310 \mathrm{kPa}$. Specimens are then cut from consolidated laminates using a wet diamond saw to the dimensions shown in Table 1. For the textile architecture used in this study, one ply is denoted as (0/90) representing the warp and fill directions in the $0^{\circ}$ and $90^{\circ}$ directions, respectively. Therefore, the laminates used in this investigation are composed of 12 plies of textile material with the warp direction oriented along the specimen's length.

A gravity accelerated drop weight impact tester is used to perform instrumented impact experiments on the flat specimens. Below the pin located flat specimen there is an unsupported central region measuring $76 \mathrm{~mm}$ by 127 $\mathrm{mm}$, corresponding to the width and length directions of the specimen, respectively. The specimen is not securely clamped; rather a pair of toggle clamps is closed with negligible force to only constrain vertical displacement of the specimen edges. The incident kinetic energy of impact, which is controlled with the mass of the crosshead and its drop height, is set at $50 \mathrm{~J}$ and $25 \mathrm{~J}$ for this investigation. The impact tip is a $19 \mathrm{~mm}$ diameter cylinder with a flat face made of stainless steel. The total mass of the crosshead assembly is $5.42 \mathrm{~kg}$. A light sensor is used to determine the velocity just prior to and after impact. The force during impact is measured with a strain gage based load cell integrated in the tup. The force response is filtered at $12 \mathrm{kHz}$ and data is collected at a frequency of approximately $820 \mathrm{kHz}$ for the entire duration of the impact event. After the rebound velocity is measured, pneumatic rebound brakes are activated to prevent a second impact event onto the specimen.

In order to visualize, measure, and delineate between damage form and location, pre and post-impact specimens are ultrasonically scanned and then imaged with 3-dimensional computed tomography (CT). These methods provide metrics for the qualitative validation of finite element simulations.

$\mathrm{CT}$ is commonly used is non-destructive evaluation in order to visualize matrix cracks, delaminations and fiber breaks in carbon reinforced polymer composites. In fact, certain CT technologies can effectively delineate submicron damage in composites [26-28]. These studies have shown CT to provide insight into the spatial distribution of damage and the specific form of damage. CT scanning for this study is performed using a $225 \mathrm{KeV}$ energy level and a target power of $54 \mathrm{~W}$.

While CT provides high resolution insight into the form and distribution of damage, it requires substantial time and effort in order to delineate damage for model validation purposes. A simpler approach that has been proved useful in visualizing damage in CFRP laminates is Ultrasonic scanning. For example, Aymerich and Meili compare ultrasonic to CT visualizations and show ultrasonic scans can provide comparable resolution to CT [28]. Ultrasonic scans measure signal attenuation in a damaged specimen. The result is a $2 \mathrm{D}$ representation of the damage profile. The amplitude of the back face reflection is plotted in these images and a corresponding scale is shown to quantify the degree of attenuation. A color coding with a large value of AMP $\%$ can be attributed to undamaged and well coupled material, allowing the input sound wave to pass through the specimen and return back to the transducer with virtually no losses. Conversely, low values of returned signal amplitude are attributed to attenuation of the signal to 
regions where damage is present, i.e. delamination, cracking, etc. Ultrasonic scanning is performed using a $5 \mathrm{MHz}$ transducer with a focal length of 2 inches with specimens submerged in water to act as a coupling agent. All specimens are adequately baked out after water exposure before mechanical testing.

\section{Experimental Results}

Specimens are impacted at an incident kinetic energy of approximately $50 \mathrm{~J}$. A second set of impact experiments with $25 \mathrm{~J}$ of incident kinetic energy are conducted to validate the model after necessary adjustments. Both measured force time history data sets are shown in Figure 1. The impact event consisted of a combination of elastic deformation and rebound as well as energy absorbing damage, with the entire event occurring in approximately $5 \mathrm{~ms}$. A summary of the results is shown in Table 2 .

The specimens underwent pre and post-impact scans using ultrasonics and 3D computed tomography. Typical $\mathrm{CT}$ results are shown in Figure 2. The top-down view slices through the specimen reveal the extent of shear cracking and gross delamination. This top-down view is not able to detect delaminations that are in contact as well as the ultrasonic scans. However, slices along the length of the specimen reveal at which interfaces delamination has occurred and the extent at which it has grown.

\section{Numerical Model}

\section{Finite Element Code and Mesh}

The finite element mesh consists of the lower impactor geometry, a lumped mass, a fixed holder and base, and the specimen. The experiments consistently showed crack preference towards one side of the test fixture; indicating skew impact of the tup on the specimen. This angle of impact was measured as $0.45^{\circ}$. Since this error was only observed on one of the principal axes, the model is half symmetric.

Verification of the model and code is done using mesh convergence studies, and regression tests are performed for most of the physics that are present in the simulation (i.e. contact, constitutive models, element formulation, etc.). The laminate material model was generated in conjunction with this study, so verification was completed on the theoretical formulation by subject matter experts and numerical outputs. These outputs used various representative simulations, such as single element, implicit quasi-static and explicit dynamic crack growth for mesh sensitivities.

The final converged mesh consists of 1.1 million reduced integration hexahedral elements with a default "hourglass stiffness" of 0.05 . Each lamina interface is modeled as a plane separated by cohesive zone (CZ) zero volume hexahedral elements in order to capture delamination failure. Therefore, there are 23 elements through the thickness of the laminate, 12 solid hexahedral and $11 \mathrm{CZ}$ surface elements. No local mesh refinement is utilized. As a result of the composite failure constitutive model formulation, mesh convergence does not indicate mesh independence since the mesh size is an input.

All simulations are completed using Sandia National Laboratories' Sierra Solid Mechanics code Presto. Presto is a Lagrangian, three-dimensional code for the finite element analysis of solid structures and is suitable for explicit dynamic analyses [29].

\section{Materials}

An elastic orthotropic damage evolution and failure material model is developed for this study. The formulation follows closely with [30-32]. Crack band theory is implemented, where distributed crack growth is assumed through a localization event. Prior to softening, distributed damage is allowed to evolve in the element resulting in a "hardening" stress strain response. Failure, or crack localization, is assumed to be distributed across the crack band and softening is controlled by size dependent fracture energy [33]. The opening stress to relative displacement $(\delta)$ relationship is therefore replaced with the presumed identical $\delta=\varepsilon l^{*}$. Where, for our purposes, $l^{*}$ is the characteristic length of the finite element and $\varepsilon$ is the homogenized strain in the crack opening direction [32]. Since elastic damage is assumed the only source of stiffness loss, damage variables, designated $d_{i j}$, can be introduced for each the normal and shear components of stress. The evolution of the individual damage components will be discussed later in this section. The corresponding compliance tensor takes on the following form [30]: 


$$
\mathbf{S}=\left[\begin{array}{cccccc}
\frac{1}{E_{11}\left(1-d_{11}\right)} & \frac{-v_{21}}{E_{22}} & \frac{-v_{31}}{E_{33}} & 0 & 0 & 0 \\
\frac{-v_{12}}{E_{11}} & \frac{1}{E_{22}\left(1-d_{22}\right)} & \frac{-v_{32}}{E_{33}} & 0 & 0 & 0 \\
\frac{-v_{13}}{E_{11}} & \frac{-v_{23}}{E_{22}} & \frac{1}{E_{33}\left(1-d_{33}\right)} & 0 & 0 & 0 \\
0 & 0 & 0 & \frac{1}{2 G_{12}\left(1-d_{12}\right)} & 0 & 0 \\
0 & 0 & 0 & 0 & \frac{1}{2 G_{13}\left(1-d_{13}\right)} & 0 \\
0 & 0 & 0 & 0 & 0 & \frac{1}{2 G_{23}\left(1-d_{23}\right)}
\end{array}\right]
$$

The damaged (actual) stresses and strains are

where

$$
\begin{aligned}
& \sigma_{i j}=C_{i j k l} \varepsilon_{k l} \\
& \varepsilon_{i j}=S_{i j k l} \sigma_{k l}
\end{aligned}
$$

$$
C_{i j k l}=S_{i j k l}^{-1}
$$

Since the compliance tensor becomes singular at $d=1$, the stiffness tensor is written in closed form where the limit of stiffness as $d \rightarrow 1$ exists.

In order to simplify the model and model form error analysis, the general form of the damage activation function is assumed a simple quadratic strain criterion. These thresholds are evaluated for tension and compression, matrix and fiber modes and for each of the primary material planes [2, 31, 32]. For example, the damage activation function for the matrix mode in the 11 plane is given for tension and compression as

Tension:

$$
\varphi_{11+}^{m}=\sqrt{\left(\frac{E_{11}\left\langle\varepsilon_{11}\right\rangle}{X_{11+}^{m}}\right)^{2}+\left(\frac{G_{12} \gamma_{12}}{S_{12}^{m}}\right)^{2}+\left(\frac{G_{13} \gamma_{13}}{S_{13}^{m}}\right)^{2}}
$$

Compression:

$$
\varphi_{11-}^{m}=\sqrt{\left(\frac{E_{11}\left\langle-\varepsilon_{11}\right\rangle}{X_{11-}^{m}}\right)^{2}+\left(\frac{G_{12} \gamma_{12}}{S_{12}^{m}}\right)^{2}+\left(\frac{G_{13} \gamma_{13}}{S_{13}^{m}}\right)^{2}}
$$

where \langle\rangle are the Macaulay brackets, defined as

$$
\langle x\rangle= \begin{cases}0, & x<0 \\ x, & x \geq 0\end{cases}
$$

The user provides only damage initiation/failure stresses $\left(X^{f}\right)$. For failure in the fiber mode the stress used in the damage activation function must be the effective stress. For strain equivalency, the effective strength in the 11 direction is simply

$$
\bar{X}^{f}=E_{11} \varepsilon_{11}^{f}
$$

where $\varepsilon_{11}^{f}$ is the strain to failure found by solving strain during matrix damage curve at the fiber strength. Therefore, the damage activation function for the fiber mode in the 11 plane is given for tension and compression as 
Tension:

$$
\varphi_{11+}^{f}=\sqrt{\left(\frac{E_{11}\left\langle\varepsilon_{11}\right\rangle}{\bar{X}_{11+}^{f}}\right)^{2}+\left(\frac{G_{12} \gamma_{12}}{\bar{S}_{12}^{f}}\right)^{2}+\left(\frac{G_{13} \gamma_{13}}{\bar{S}_{13}^{f}}\right)^{2}}
$$

Compression:

$$
\varphi_{11-}^{f}=\sqrt{\left(\frac{E_{11}\left\langle-\varepsilon_{11}\right\rangle}{\bar{X}_{11-}^{f}}\right)^{2}+\left(\frac{G_{12} \gamma_{12}}{\bar{S}_{12}^{f}}\right)^{2}+\left(\frac{G_{13} \gamma_{13}}{\bar{S}_{13}^{f}}\right)^{2}}
$$

The user specified fracture energies are the total energy associated with material bifurcation for a given mode of failure. The current model formulation does not account for mixed mode coupling during fracture.

This formulation assumes linear elastic behavior of the composite prior to any damage evolution and ignores non-linear elastic and viscous dissipation that can be present in polymeric materials. Therefore, matrix damage, with activation functions described in Equations (5) and (6), is manifested as proportional damage to the homogenized linear elastic stiffness of the composite lamina.

Damage evolution is user defined only for matrix mode failure. The evolution of fiber damage is controlled by internal parameters using the fracture energies and crack band theory. For each matrix failure mode (tension, compression, shear) the evolution equation is generally defined as

$$
d=1-\frac{K_{m}}{E}+\left(\frac{K_{m}}{E}-1\right) \frac{1}{r_{m}^{n}}
$$

where $K_{m}$ and $n$ are the matrix mode damage modulus and exponent, respectively. The damage exponent is intended to add flexibility in the material response. For shear damage, $K_{m}$ is defined in $\tau-\gamma$ space. After the fiber mode strength is exceeded, the material is linearly softened. Note matrix mode damage is zero for $K_{m}=E$ or $n=0$.

In order to determine the significance of material input parameters, a sensitivity analysis is conducted. The analysis of variance (ANOVA) general linear regression method is a way to test the hypothesis that the inputs to the model (factors) within given tolerances do not significantly affect the means of an output metric. A Box-Behnken design of experiments method is used to assign factors at different levels for individual runs [34]. The results of this study are not presented here.

The properties for the 8HS CFRP are shown in Table 3. Standard deviations for measured parameters are given in parentheses and bounds of uniform distributions for estimated parameters are shown as \pm . Very large ranges where often utilized in the sensitivity analysis due to lack of decent predictions. Once deemed influential, the parameters are better estimated. The failure model is complex and requires an extensive experimental program to characterize. Some properties, such as the in-plane compressive strength, are calibrated to experiments that exhibit a specific phenomenon of interest. Other properties are estimated from literature or calculated through micromechanical simulations [35, 36]. Properties not directly measured are given bounds, thus assuming a uniform distribution between two likely extrema. Each measured property is either applied directly and verified or calibrated to match experiments.

A simple mixed mode traction separation law detailed in [37] is used for delamination prediction. Interpenetration is prevented with contact definition. This precaution is necessary to prevent layer interpenetration after cohesive element failure. A benefit of this technique is the appearance of compression dependent mode II peak traction and thus toughness similar to [38]. Therefore, for a constant normal stress $\left(\sigma_{n}\right)$, the effective peak traction and toughness are simply

$$
\begin{gathered}
\tau^{*}=\tau+\mu\left\langle-\sigma_{n}\right\rangle \\
G_{I I}^{*}=G_{I I}+\mu \delta_{T C}\left\langle-\sigma_{n}\right\rangle
\end{gathered}
$$

where $\mu$ is the frictional coefficient and $\delta_{T C}$ is the critical tangential separation. Since after element failure a frictional interface is assumed, the current model cannot differentiate surfaces enclosing a failed element, i.e. a single friction coefficient controls both $\mathrm{CZ}$ traction and frictional forces. The model form is known to be in error in this regard. Calibrating this method with experimental data was not complete. Conservative values were used in order to provide some level of effectiveness. The actual level of mode II toughness sensitivity on compressive stress in likely higher, as seen in [39]. 
Double cantilever beam (DCB) and end notched flexure (ENF) specimens are used to characterize the mode I and mode II interlaminar fracture toughnesses, respectively. In the ENF experiments, the crack grows unstably from the initial strength, thus not allowing for a detailed analysis of the fiber bridging effect or an accurate measurement of the average toughness. Furthermore, examination of the four point bend experiments show a series of events that includes a distinct stiffness loss due to mode II delamination. Numerical analyses of these experiments indicate higher fracture toughnesses than those measured with ENF. However, this experiment includes a number of assumptions and input sensitivities resulting in difficulty isolating this input. Further experiments, designed to obtain the rising resistance with crack growth and the fiber bridging effects are required. Nevertheless, the value obtained from the ENF experiment is used in the initial study; however, the source and effect of higher values are investigated later in this study. The interlaminar material properties are given in Table 4.

\section{Numerical Results and Uncertainty Quantification}

\section{Blind Comparison: 50J Impact}

Qualitative (subjective) assessment of the damage and the quantitative (objective) change in kinetic energy are used as validation metrics. Since the uncertainty distribution is unknown for many of the inputs, a uniform distribution is assumed in the sampling algorithm. Latin Hypercube Sampling (LHS) with 100 simulations is utilized to generate an ensemble of models to provide an output distribution.

A common method to determine if two normally distributed samples are of the same population is the Student's t-test [40]. In other words, the t-test can be used to test whether there is sufficient evidence to assume the model sample means are equal to the real world estimates (experiments). The p-value associated with the t-test is the probability that, if the null hypothesis of equal means were true, the differences are obtained by chance. For example: a value of 0.05 means there is 0.05 probability of error when rejecting the null hypothesis. In terms of validation, a high probability results in accepting the null hypothesis that there is insufficient justification that there is a significant difference between the model and the real world. Therefore, higher values of $p$ (typically $>0.05$ ) indicate confidence in the model.

Applying the Anderson-Darling test [41], normality is confirmed with a test statistics of 0.294 for the energy absorbed and 0.418 for the rebound velocity. Utilizing the Levene test for equal variance [42], it is confirmed that the model and experimental variances can be treated as equal. Therefore, a t-test for unrelated groups with equal variance can be used to estimate model validity. Testing the hypothesis that the model and the experiment means of the energy absorbed are equal produces a p-value of 0.095 which is greater than the commonly used critical value 0.05 . There is insufficient evidence to reject the null hypothesis. The t-statistic is then utilized to give a precision interval. The difference in the means is estimated by

$$
\delta X \approx\left(\bar{X}_{\text {model }}-\bar{X}_{\text {exper }}\right) \pm t_{\alpha / 2, d f} \hat{\sigma}_{\bar{X}_{\text {model }}-\bar{X}_{\text {exper }}}
$$

where $\bar{X}_{\text {model }}$ and $\bar{X}_{\text {exper }}$ are the model and experimental means, respectively, $t_{\alpha / 2, d f}$ is the t-test statistics at significance level of $\alpha$ and $d f$ degrees of freedom and the combined standard deviation of the difference $\left(\hat{\sigma}_{\bar{X}_{\text {model }}-\bar{X}_{\text {exper }}}\right)$ for $n_{\text {model }}$ model samples and $n_{\text {exper }}$ experiment samples is

$$
\hat{\sigma}_{\bar{X}_{\text {model }}-\bar{X}_{\text {exper }}}=S_{\text {pooled }} \sqrt{\frac{1}{n_{\text {model }}}+\frac{1}{n_{\text {exper }}}}
$$

and the pooled standard deviation assuming equal variance is

$$
S_{\text {pooled }}=\sqrt{\frac{\left(n_{\text {exper }}-1\right) S_{\text {exper }}^{2}+\left(n_{\text {model }}-1\right) S_{\text {model }}^{2}}{n_{\text {exper }}+n_{\text {model }}-2}}
$$

With $95 \%$ certainty $(\alpha=0.05$ ), the bounds in the difference (error bounds) between the model and experimental predictions for means of energy absorbed are $[-5.17,2.43]$ or $[-22.6,10.6] \%$. Similarly, the rebound velocities produce a p-value of 0.096 and $95 \%$ error bounds of $[-0.14,0.30] \mathrm{m} / \mathrm{s}$ or $[-4.55,9.62] \%$. Therefore, a blind comparison of the quantitative results produces statistical justification for model validation. 
The delaminated area and crack characteristics are assessed to determine accuracy in the model fidelity and physical representation of failure. These qualitative validation metrics are used to ensure accuracy in damage form and distribution. Figures 3(a) and (b) provide a typical CT scan of a tested specimen and the fiber damage and delamination accumulated in the model, respectively. This comparison was completed on a select few preliminary models with input parameters fixed at the mean values given in Table 3 and Table 4 . While the experiment shows a more resolved crack and a more distributed delamination pattern, the physical characteristics match well with the model. The length and position of the main crack extending axially (into the page) matches experiments. Figures 4(a) and (b) show a random selection of experimental and model delamination areas, respectively. These results show a silhouette view of delamination shape and extent in order to compare directly to the ultrasonic scans and are not meant to indicate the depth of the delamination. A threshold criterion of $10 \%$ fracture energy absorbed in the cohesive zone elements is used to generate these plots. A discrepancy exists in the extent of delamination. Nearly all the models predicted delamination to a free edge, while nearly all the experiments exhibited contained delamination. However, the actual area of delamination was not explicitly measured. Overall, the qualitative properties matched well between model and experiment.

Figure 5 gives force versus time for all the simulations and experiments. While both the homogenized quantitative metrics and qualitative aspects of the model match well with experiments, there are many important discrepancies to note. The first peak in the simulations, corresponding to delamination initiation, is much lower and almost non-existent compared to the experiments. The remaining load in the simulations, corresponding to damage evolution and elastic loading, is substantially lower compared to the experiments. The period of impact in the simulations is also considerably greater. The combination of these discrepancies does produce an average or homogenized response similar to the experiments. However, it is clear that the rate, timing and form of damage evolution are substantially different. Noting these discrepancies and evaluating the sensitivity analysis results, the estimated parameters of importance can be calibrated to produce a response that is qualitatively and quantitatively similar to the experiments.

\section{Model Form Errors: Rate Effects and Fiber Bridging}

The model form errors are isolated utilizing the qualitative assessment of the blind study and the sensitivity analysis results. Through data analysis and calibration, the sharp peak at first failure is a result of delamination and lamina crack evolution. This is consistent with the model, which predicted delamination and crack growth to occur in much the same way yet more gradually and at a lower load. The higher loads in the experiments must be associated with a higher effective strength likely due to rate effects. Additionally, models that predict delamination to an edge produce high energy absorptions; however, the force time history does not match in the unload portion of the response. With little exception, in order to match the experimental force time history, two fully contained planes of delamination are needed.

In order to rectify differences in each metric of validation, the following errors are progressively addressed. First, extrinsic toughening due to fiber bridging is added as a superimposed traction separation law that will control crack arrest before reaching a free edge. Second, rate effects are added to the traction separation relationship in order to predict rate dependent delamination. Third, lamina failure and damage evolution criteria are modified to better reflect the sudden fracture seen in the experiments.

A simple cohesive zone material model is implemented in order to address the issue of rate dependent crack initiation and extrinsic toughening due to fiber bridging. The cohesive zone material model utilizes two superimposed mixed mode traction separations laws in order to predict extrinsic toughing due to fiber bridging [43]. The general form of the traction separation law is shown in Figure 6. Four independent damage evolutions are tracked for each of the fiber and matrix for mode I and mode II. In order to account for mixed mode failure, the element is fully decayed when the following criterion is met:

$$
\frac{\Gamma_{I}}{G_{I C}}+\frac{\Gamma_{I I}}{G_{I I C}}=1
$$

where $\Gamma_{I}$ and $\Gamma_{I I}$ are the total energies per unit area for mode I and II, respectively and $G_{I C}$ and $G_{I I C}$ are the instantaneous mode I and II fracture toughnesses, respectively. An example of the fiber bridging effect and a recalibration of the DCB force versus displacements are shown in Figure 7. Additionally, an example of the effects of fiber bridging on a delaminated surface after impact is shown in Figure 8. The faded color in the fiber bridging Figure 8(b) is matrix only failure and only partial fiber failure. From this figure, it is noted the fiber bridging model still has two major planes of delamination and does not change the fracture path in the lamina while mandating 
contacted delamination. While mode II fiber bridging is not experimentally determined, the phenomenon is noted in literature [44].

The rate effects are added with a simple log linear relationship on the peak stresses. The length scale and separation values remain constant. Therefore, the initial slope, and fracture toughnesses follow the same log linear relationship. The inputs are adjusted at the beginning of each time step by

$$
f=\bar{f}\left(1+C_{r} \log \left(\frac{\dot{\varepsilon}}{\dot{\varepsilon}_{o}}\right)\right)
$$

where $\bar{f}$ and $f$ are the parameters at strain rates $\dot{\varepsilon}_{o}$ and $\dot{\varepsilon}$, respectively and $C_{r}$ is the strain rate coefficient. The reference strain rate $\left(\dot{\varepsilon}_{o}\right)$ is typically $10^{-4}$. The strain rate is estimated as the separation rate over some artificial thickness, typically an estimate of the bond line. For exploratory purposes, the above rate effects are included in the out-of-plane shear strengths of the lamina.

The rising resistance in mode I is characterized with the DCB experiment. The fracture energy is plotted versus the crack length. If the rising resistance is assumed due to extrinsic toughening (behind the crack tip), the initial and total fracture energies and the normal length scale are easily extracted from the data. This method is not possible for mode II given the data available. The four point ENF experiment can be used to extract the necessary data [45]. However this method is shown to be highly sensitive to friction and experimental set-up. For this study, the extrinsic toughening in mode II is applied with engineering judgment and numerical calibration. The normal and tangential fiber bridging length scales are chosen to be $4 \mathrm{~mm}$ and $2 \mathrm{~mm}$, respectively. The normal length scale and toughness are calibrated to match the experimental data.

A side effect of the higher interlaminar strength and toughness due to rate effects is a greater sensitivity to the timing and distribution of lamina damage and failure. If the lamina damages over a long period with a large distribution of cracks, interlaminar stresses remain low and often below the failure point. Therefore, the out-ofplane shear stress is modeled as linear elastic to failure, removing any matrix damage. Additionally, the shear compressive failure coupling is likely in error. The simple quadratic strain formation under predicts the effective strength in out-of-plane compression and shear conditions. The model form is likely better represented by an unbalanced partially interactive criterion [39, 46, 47]. In order to test this modification without significant effort, the out-of-plane compressive failure is removed; reducing the failure criteria to maximum strain. This effectively increases the load at failure while reducing the period of lamina crack formation. The effect is lamina crack evolution and delamination occurring simultaneously; resulting in the sudden load drop seen in the experiments. Lastly, the compression sensitivity in mode II delamination is shown to be too high. Upon crack initiation at lamina failure, the "frictional" loads prevent significant shallow delamination; resulting in a greater driving force in the intact laminate. The result is delamination to an edge and an over prediction in the energy absorbed. Therefore, the "frictional" coefficient used in compression shear coupling is reduced to a mean value of 0.20 .

The various model form and calibration changes are demonstrated by a single model. Table 5 provides the modified model inputs; all other inputs are taken as the means. Due to the change in delamination model form, the inputs must be recalibrated. The values used for mode I delamination, namely the matrix and fiber-bridging toughnesses or $G_{I C m}$ and $G_{I C f}$, respectively, are calibrated to the DCB experimental data. The mode II matrix toughness $\left(G_{I I C m}\right)$ remains unchanged and the fiber-bridging toughness $\left(G_{I I C f}\right)$ is set to be the same fraction of matrix toughness as in the mode I values. The rate effects inputs are estimated from literature and are not measured [39].

Table 6 give the energy absorbed for each scoping simulation described below. Figures 9(a)-(d) show the force versus time results for the sequence of modifications described above. The models designated A-E in Figures 9(a)-(d) are as follows:

A. Original model with the mean inputs given in Table 3 and Table 4

B. The original plus fiber bridging

C. The original plus fiber bridging, rate effected delamination, no out-of-plane shear matrix damage, no outof-plane compressive failure

D. The original plus fiber bridging, rate affected delamination, no out-of-plane shear matrix damage, no outof-plane compressive failure, "friction" coefficient reduced to 0.20 .

E. The original plus fiber bridging, rate effected delamination, no out-of-plane shear matrix damage, no outof-plane compressive failure, "friction" coefficient reduced to 0.20 , rate effects on out-of-plane shear strength in the lamina 
The original model (A) contains all the deficiencies described in the preceding section. With the addition of fiber bridging in model B, all three primary deficiencies (first peak, post-delamination loads and impact period) are improved. Model C combines rate effects and modifications to the lamina failure criteria. Including only the later modification (not shown) did not substantially change the load response and was only noticed in the damage pattern. Therefore, it is clear that the rate effects are primarily responsible for producing the correct first peak force. Model $\mathrm{D}$ has a reduction of the friction coefficient between delaminations. This change produces more accurate delamination patterns, period of impact and load drop after delamination. Finally, Model E is included in order to demonstrate rate effects in the lamina response. This change results in over prediction on the first peak force but more accurate post-delamination loads.

While there remains other additional model physics that can be included; those presented in this section are proposed sufficient to produce another round of validation simulations. While the rate effects in the bulk material show promise, Model D, which includes rate effects in delamination and modified lamina failure, is deemed adequate to produce quantitative and qualitative model validation. First, a sampling of the 50J models is simulated and the results are compared to experimental data. Secondly, the 25J experiments are modeled in order to produce an additional blind comparison for validation.

\section{Verification of the Modified Model: 50J}

Since the model has been adjusted to 50J impact experiments, this exercise can only serve as a verification and further calibration of the model rather than a true validation. The means of the modified inputs are given in Table 5. The total toughnesses in the cohesive model are assumed to have the same standard deviation as previously. The proportion range in the shear fracture energies are assumed unchanged. The uncertainties in the rate coefficients are assumed uniformly $\pm 10 \%$. A total 100 samples are simulated with LHS.

The force time histories, shown in Figure 10, compare well. The first peak load, the drop in load due to delamination and lamina failure, the second peak and the duration of impact all compare well. Additionally, the lamina damage and failure match well to experiments. However, even when preliminary analysis showed promise for a contained delamination, the delaminations in these samplings remain an issue. One of the six experiments has delamination to a free edge. In contrast, in the simulations nearly all the lower delaminations propagated to a free edge. Fiber bridging effectively maintained the average shear stiffness necessary to match the unload path in the experiments; however, the extent of delamination is dissimilar. The formulation of rising resistance may be in error.

The simulated energy absorbed results show a bimodal distribution with one outlier. While the simulations are weighted towards the higher energy mode, the bimodal delamination and force versus time of the experiments is well represented. However, more experiments would be necessary to accurately characterize the bimodal distribution.

After removing the outlier of $27.4 \mathrm{~J}$, the quantitative results based on energy absorbed compare well. Equal variance is confirmed with the Levene test and a p-value of 0.164 . However, as the distribution is bimodal, normality cannot be confirmed in the numerical results. Therefore, the Mann-Whitney [48] non-parametric rank test is utilized for the energy absorbed. This method will test for the equality of the medians between two groups and does not rely on the data being normally distributed. The medians of the experimental and model data are $23.0 \mathrm{~J}$ and 23.4 J, respectively. Testing the null hypothesis of equal medians between the model and experiment produces a pvalue of 0.798 . Since the p-value is greater than 0.05 , there is insufficient justification to reject the null-hypothesis. Therefore, quantified verification of the updated model is achieved. The $95 \%$ error bounds on the difference in the medians are estimated as $[-1.20,1.57] \mathrm{J}$ or $[-5.21,6.85] \%$.

\section{Blind Comparison of the Modified Model: 25J}

To test the predictive capability of the updated model, an impact energy was chosen to be significantly different than the previous value while still activating similar phenomenon. The $50 \mathrm{~J}$ experiments showed recoverable loading (matching elastic predictions) up to approximately $25 \mathrm{~J}$ of energy transfer. Therefore, we chose this challenging impact energy for final validation experiments and simulations.

A total 100 samples are simulated with LHS. While the force time histories, shown in Figure 11, cover the range of experimental values, the scatter is significant. This is likely due to the instability of the chosen input energy. Nevertheless, the first peak load and the drop in load due to delamination compare well. Additionally, the lamina damage and failure and delaminated surface match well to experiments. Random selections of delaminated surfaces from both the experiments and the models are shown in Figures 12(a) and (b), respectively. Some 
simulations show delamination to a free edge. This discrepancy may further point to the formulation of rising resistance being in error.

After removing the outlier of $1.60 \mathrm{~J}$, the quantitative results based on energy absorbed compare well. Similar to the calibrated $50 \mathrm{~J}$ simulations, the energy absorbed is a bimodal distribution with the one outlier. Therefore, a nonparametric test is necessary. The medians of the experimental and model data are 10.85 and $12.2 \mathrm{~J}$, respectively. The Mann-Whitney test produces a p-value of 0.832. Again, there is insufficient justification to reject the nullhypothesis. Therefore, quantified validation of the updated model is achieved. The $95 \%$ error bounds on the median are estimated as $[-2.49,1.77] \mathrm{J}$ or $[-22.9,14.2] \%$. The large uncertainty is reflective of the scatter in the simulation results arising from instability in the solution. Since the Levene test indicated unequal variances corresponding to high model uncertainty, the validation may be questionable. In order to more accurately measure the experimental variance, more data is necessary.

\section{Conclusions}

The results of this study have demonstrated a thorough verification and validation effort for the simulation of composite damage and failure under low-velocity impact. A simulation methodology and model formulation is presented with good results. Further experimentation and model development is nonetheless necessary.

For a 50J impact experiment, statistical justification in favor of the equal distribution hypothesis between the model and experiment is achieved and the uncertainty bounds are calculated. The qualitative simulation results compared well with experiments. The model predicted matrix damage, fiber breaks and delaminations consistent with experiments. However, the simulations tended to over predict the extents of delamination. Nearly all the models predicted the delaminated areas reaching a free edge of the specimen. This phenomenon was only observed in a few experimental specimens. While a rising resistance to delamination is obvious from this study, the form and/or inputs to the extrinsic toughening formulation are in question. A more detailed investigation with additional experiments is necessary. Similar results are found in the $25 \mathrm{~J}$ impacts. The qualitative results matched very well. At this point it is certain that better characterization data is necessary, however, constitutive model modification, particularly cohesive zone materials and damage surface formulation, is not ruled out.

\section{acknowledgements}

The authors are appreciative to those that contributed to this work and would like to specifically recognize the efforts of Tim Gilbertson and Alan Moore for composite laminate consolidation, Karin Krafcik for performing the ultrasonic imaging, David Moore, Kyle Thompson, Carl Jacques and Burke Kernen for the computed tomography imaging, as well as Patricia Hough for aid with statistics methodology. All funding was provided by Sandia National Laboratories which is a multi-program laboratory managed and operated by Sandia Corporation, a wholly owned subsidiary of Lockheed Martin Corporation, for the U.S. Department of Energy's National Nuclear Security Administration under contract DE-AC04-94AL85000.

\section{References}

[1] Martín-Santos E, Maimí P, González EV, Cruz P. A continuum constitutive model for the simulation of fabricreinforced composites. Composite Structures. 2014;111:122-9.

[2] User's Manual for LS-Dyna MAT162 Unidirectional and Plain Weave Composite Progressive Failure Models. Newark, DE: Center for Comp. Mat., 2011.

[3] Choi HY, Chang FK. A Model for Predicting Damage in Graphite/Epoxy Laminated Composites Resulting from Low-Velocity Point Impact. J Comp Mat. 1992;26:2134-69.

[4] Richardson MOW, Wisheart MJ. Review of low-velocity impact properties of composite materials. Composites Part A: Applied Science and Manufacturing. 1996;27:1123-31.

[5] Sjoblom PO, Hartness JT, Cordell TM. On Low-Velocity Impact Testing of Composite Materials. J Comp Mat. 1987;22:30-52.

[6] Belingardi G, Vadori R. Low velocity impact tests of laminate glass-fiber-epoxy matrix composite material plates. International Journal of Impact Engineering. 2002;27:213-29.

[7] Robinson P, Davies GAO. Impactor mass and specimen geometry effects in low velocity impact of laminated composites. International Journal of Impact Engineering. 1992;12:189-207.

[8] Aslan Z, Karakuzu R, Okutan B. The response of laminated composite plates under low-velocity impact loading. Composite Structures. 2003;59:119-27. 
[9] Caputo F, De Luca A, Lamanna G, Borrelli R, Mercurio U. Numerical study for the structural analysis of composite laminates subjected to low velocity impact. Comp Part B. 2014;67:296-302.

[10] Richardson MOW, Wisheart MJ. Review of low-velocity impact properties of composite materials. Comp Part A. 1996;27:1123-31.

[11] Zukas JA, Nicholas T, Swift HF, Greszczuk LB, Curran DR. Impact Dynamics. New York: John Wiley \& Sons, 1982.

[12] Shivakumar K, Elber W, Illg W. Prediction of low velocity impact damage in thin circular laminates. AIAA Journal. 1985;23:442-9.

[13] Sjoblom PO, Hartness JT, Cordell TM. On low-velocity impact testing of composite materials, Journal of Composite Materials. J of Comp Mat. 1988;22:30-52.

[14] Olsson R. A review of impact experiments at FFA during 1986 to 1998, FFA TN 1999-08. Bromma: The Aeronautics Research Institute of Sweden, 1999.

[15] Zhou G. Prediction of impact damage thresholds of glass fibre reinforced laminates. Comp Struct. 1995;31:18593.

[16] Aslan Z, Karakuzu R, Okutan B. The response of laminated composite plates under low velocity impact loading. Comp Struct. 2003;59:119-27.

[17] Baucom JN, Zikry MA. Low velocity impact damage progression in woven E-glass composite systems. Comp Part A. 2005;36:658-64.

[18] Cantwell WJ, Morton J. Geometrical effects in the low velocity impact response of CFRP. Comp Struct. 1989;12:39-59.

[19] Zhang J, Zhang X. Simulating low-velocity impact induced delamination in composites by a quasi-static load model with surface-based cohesive contact. Composite Structures. 2015;125:51-7.

[20] Yu G-C, Wu L-Z, Ma L, Xiong J. Low velocity impact of carbon fiber aluminum laminates. Composite Structures. 2015;119:757-66.

[21] Shi Y, Pinna C, Soutis C. Modelling impact damage in composite laminates: A simulation of intra- and interlaminar cracking. Composite Structures. 2014;114:10-9.

[22] Guide for Verification and Validation in Computational Solid Mechanics. In: ASME, editor. New York, NY: American Society of Mechanical Engineers; 2006.

[23] Davies GAO, Zhang X. Impact damage prediction in carbon composite structures. International Journal of Impact Engineering. 1995;16:149-70.

[24] Harizi W, Chaki S, Bourse G, Ourak M. Mechanical damage characterization of glass fiber-reinforced polymer laminates by ultrasonic maps. Comp Part B. 2015;70:131-7.

[25] English S, Nelson S, Briggs T, Brown A. Verification and Validation of Carbon-Fiber Laminate Low Velocity Impact Simulations. Livermore, CA: Sandia National Laboratories; 2014.

[26] Scott AE, Mavrogordato M, Wright P, Sinclair I, Spearing SM. In situ fibre fracture measurement in carbonepoxy laminates using high resolution computed tomography. Composites Science and Technology. 2011;71:14717.

[27] Wright P, Fu X, Sinclair I, Spearing SM. Ultra High Resolution Computed Tomography of Damage in Notched Carbon Fiber-Epoxy Composites. Journal of Composite Materials. 2008;42:1993-2002.

[28] Aymerich F, Meili S. Ultrasonic evaluation of matrix damage in impacted composite laminates. Composites Part B: Engineering. 2000;31:1-6.

[29] Team SS. SIERRA/SolidMechanics 4.28 User's Guide. Albuquerque, NM.: Sandia National Laboratories, 2013.

[30] Matzenmiller A, Lubliner J, Taylor R. A constitutive model for anisotropic damage in fiber-composites. Mech of Mat. (1995);20:125-52.

[31] Maimí P, Camanho P, Mayugo J, Dávila C. A continuum damage model for composite laminates: Part I Constitutive model. Mech of Mat. (2007);39:897-908.

[32] Maimí P, Camanho P, Mayugo J, Dávila C. A continuum damage model for composite laminates: Part II Computational implementation and validation. Mech of Mat. (2007);39:909-19.

[33] Bazant ZP, Oh BH. Crack band theory for fracture of concrete. Matériaux et Construction. 1983;16:155-77.

[34] S. F, Bruns R, Ferreira H, Matos G, David J, Brandao G, et al. Box-Behnken Design: An Alternative for the Optimization of Analytical Methods. Analytica Chimica ACTA. 2007;597:179-86.

[35] English SA, Brown A, Briggs T. A Micro to Macro Approach to Polymer Matrix Composites Damage Modeling: Final LDRD Report. Livermore, CA: Sandia National Laboratories; 2013.

[36] Barbero EJ, Lonetti P, Sikkil KK. Finite element continuum damage modeling of plain weave reinforced composites. Comp Part B. 2006;37:137-47. 
[37] Li S, Thouless M, Waas A, Schroeder J, Zavattieri P. Mixed-mode Cohesive-zone Models for Fracture of an Adhesively-bonded Polymer-matrix Composite. Eng Fract Mech. (2006);73:64-78.

[38] Gan KW, Hallett SR, Wisnom MR. Measurement and modelling of interlaminar shear strength enhancement under moderate through-thickness compression. Comp Part A. (2013);49:18-25.

[39] Daniel I, Werner B, Fenner J. Strain-rate-dependent failure criteria for composites. Comp Sci and Tech. 2011;71:357-64.

[40] Navidi W. Statistics for Engineers \& Scientists. 4th ed. New York, NY: McGraw-Hill Education, 2011.

[41] D’Augostino R, Stephen M. Goodness-of-fit Techniques. New York, NY: Marcel Dekker, 1986.

[42] Levene H. Robust testes for equality of variances. In: Olkin I, editor. Contributions to Probability and Statistics. Palo Alto, CA: Stanford Univ. Press; 1960. p. 278-92.

[43] Sills RB, Thouless MD. Cohesive-length scales for damage and toughening mechanisms. Int J Solids Struct. 2014.

[44] Anyfantis KN, Tsouvalis NG. Characterization of Fiber Bridging in Mode II Fracture Growth of Laminated Composite Materials. Appl Mech and Mat. 2010;24-25:245-50.

[45] Kageyama K, Kimpara I, Suzuki T, Ohsawa I, Kanai M, Tsuno H. Effects of Test Conditions on Mode II Interlaminar Fracture Toughness of Four-Point ENF Specimens. ICCM 12. Paris, France1999.

[46] Daniel I, Luo J, Schubel P, Werner B. Interfiber/interlaminar failure of composites under multi-axial states of stress. Comp Sci and Tech. 2009;69:764-71.

[47] Sun CT, Quinn BJ, Tao J. Comparative Evaluation of Failure Analysis Methods for Composite Laminates US DOT; 1996.

[48] Mann HB, Whitney DR. On a Test of Whether one of Two Random Variables is Stochastically Larger than the Other. Annals of Math Stat. 1947;18:50-60. 


\section{List of Figures}

Figure 1: Force versus time from experiments

Figure 2: Typical CT slices along depth and the specimen length showing respective cross sections after impact

Figure 3: An example of the post impact cross-section of (a) CT scanned specimen and (b) model prediction of fiber damage and delamination.

Figure 4: A selection of delaminated areas for (a) experiments and (b) simulations

Figure 5: Force versus time from simulations and experiments

Figure 6: Formation of the modified traction-separation law

Figure 7: Comparison of cohesive zone models with experimental data

Figure 8: Example of delaminated areas from 50J simulations for (a) original and (b) fiber bridging

Figure 9: Force versus time from simulations with fiber bridging and rate sensitive delamination

Figure 10: Force versus time from 50J simulations and experiments

Figure 11: Force versus time from 25J simulations and experiments

Figure 12: A random selection of $25 \mathrm{~J}$ delaminated areas for the (a) experiments and (b) the updated model

\section{List of Tables}

Table 1: Typical dimensions for impact specimens

Table 2: Measured impact parameters. Values are shown as means and (standard deviations)

Table 3: CFRP material properties

Table 4: Interlaminar material properties

Table 5: CFRP input material properties for scoping

Table 6: Energy absorbed predictions for scoping exercise 
Table 1: Typical dimensions for impact specimens

\begin{tabular}{|l|l|l|l|}
\hline Width $(\mathrm{mm})$ & Length $(\mathrm{mm})$ & Thickness $(\mathrm{mm})$ & Stack Sequence \\
\hline 102 & 155 & 4.49 & {$\left[(0 / 90)_{6}\right]_{s}$} \\
\hline
\end{tabular}


Table 2: $\quad$ Measured impact parameters. Values are shown as means and (standard deviations)

\begin{tabular}{|c|c|c|c|c|c|c|}
\hline $\begin{array}{l}\text { Target } \\
\text { impact } \\
\text { energy }(\mathrm{J})\end{array}$ & $\begin{array}{l}\text { Impact } \\
\text { Velocity } \\
(\mathrm{m} / \mathrm{s})\end{array}$ & $\begin{array}{l}\text { Impact } \\
\text { Energy } \\
(\mathrm{J})\end{array}$ & $\begin{array}{l}\text { Maximum } \\
\text { Load }(N)\end{array}$ & $\begin{array}{l}\text { Energy } \\
\text { Absorbed } \\
(J)\end{array}$ & $\begin{array}{l}\text { Impact } \\
\text { Duration } \\
(\mathrm{ms})\end{array}$ & $\begin{array}{l}\text { Rebound } \\
\text { Velocity } \\
(\mathrm{m} / \mathrm{s})\end{array}$ \\
\hline 50.0 & $\begin{array}{c}4.3 \\
(0.002)\end{array}$ & $\begin{array}{c}49.1 \\
(0.047)\end{array}$ & $\begin{array}{c}13575.1 \\
(317.8)\end{array}$ & $\begin{array}{c}22.9 \\
(0.953)\end{array}$ & $\begin{array}{c}5.0 \\
(0.069)\end{array}$ & $\begin{array}{c}3.1 \\
(0.058)\end{array}$ \\
\hline \multirow{2}{*}{25.0} & 3.06 & 25.4 & 12120 & 11.1 & 4.76 & 2.30 \\
$(0.0008)$ & $(0.012)$ & $(132)$ & $(0.64)$ & $(0.11)$ & $(0.057)$ \\
\hline
\end{tabular}


Table 3: $\quad$ CFRP material properties

\begin{tabular}{|c|c|c|}
\hline Description & Identification & Values \\
\hline \multicolumn{3}{|c|}{ Elastic Constants } \\
\hline Warp Modulus & $E_{11}(G P a)$ & $63.9(2.4)$ \\
\hline Weft Modulus & $E_{22}(G P a)$ & $62.7(3.8)$ \\
\hline Out-of-plane Modulus & $E_{33}(G P a)$ & $8.19 \pm 0.40$ \\
\hline In-plane Poisson's Ratio & $v_{12}$ & $0.048(0.018)$ \\
\hline Weft Poisson's Ratio & $v_{23}$ & $0.399 \pm 0.018$ \\
\hline Warp Poisson's Ratio & $v_{13}$ & $0.400 \pm 0.017$ \\
\hline In-plane Shear Modulus & $G_{12}(G P a)$ & $3.44(0.058)$ \\
\hline Weft Shear Modulus & $G_{23}(G P a)$ & $3.27 \pm 0.27$ \\
\hline Warp Shear Modulus & $G_{13}(G P a)$ & $3.25 \pm 0.26$ \\
\hline \multicolumn{3}{|c|}{ Fracture Energies } \\
\hline Warp Tensile Fracture Energy & $G_{I I I}\left(\mathrm{~J} / \mathrm{mm}^{2}\right)$ & $80 \pm 20$ \\
\hline Weft Tensile Fracture Energy & $G_{I 22}\left(\mathrm{~J} / \mathrm{mm}^{2}\right)$ & $80 \pm 20$ \\
\hline In-plane Shear Fracture Energy & $G_{I I I 2}\left(\mathrm{~J} / \mathrm{mm}^{2}\right)$ & $12 \pm 1.2$ \\
\hline Weft Shear Fracture Energy & $G_{I / 23}\left(\mathrm{~J} / \mathrm{mm}^{2}\right)$ & $10 \pm 1.0$ \\
\hline Warp Shear Fracture Energy & $G_{I I I 3}\left(\mathrm{~J} / \mathrm{mm}^{2}\right)$ & $10 \pm 1.0$ \\
\hline \multicolumn{3}{|c|}{ Strengths } \\
\hline Warp Tensile Strength & $F_{l T}(M P a)$ & $769(37)$ \\
\hline Warp Compressive Strength & $F_{1 C}(M P a)$ & $-816(69)$ \\
\hline Weft Tensile Strength & $F_{2 T}(M P a)$ & $823(26)$ \\
\hline Weft Compressive Strength & $F_{2 C}(M P a)$ & $-816(69)$ \\
\hline Out-of-plane Tensile Strength & $F_{3 T}(M P a)$ & $56.2 \pm 13$ \\
\hline Out-of-plane Compressive Strength & $F_{3 C}(M P a)$ & $-56.2 \pm 13$ \\
\hline In-plane Shear Matrix Strength & $S_{I 2 M}(M P a)$ & $48.4(0.84)$ \\
\hline In-plane Shear Fiber Strength & $S_{12 F}(M P a)$ & $77.3(1.1)$ \\
\hline Weft Shear Matrix Strength & $S_{23 M}(M P a)$ & $32.4 \pm 7.4$ \\
\hline Weft Shear Fiber Strength & $S_{23 F}(M P a)$ & $65.5 \pm 12$ \\
\hline Warp Shear Matrix Strength & $S_{13 M}(M P a)$ & $32.4 \pm 7.4$ \\
\hline Warp Shear Fiber Strength & $S_{13 F}(M P a)$ & $65.5 \pm 12$ \\
\hline \multicolumn{3}{|c|}{ Damage Moduli } \\
\hline In-plane Shear Damage Modulus & $K_{12 m}(M P a)$ & $152(10.1)$ \\
\hline Weft Shear Damage Modulus & $K_{23 m}(M P a)$ & $152 \pm 15.2$ \\
\hline Warp Shear Damage Modulus & $K_{13 m}(M P a)$ & $152 \pm 15.2$ \\
\hline
\end{tabular}


Table 4: Interlaminar material properties

\begin{tabular}{|l|l|l|}
\hline Description & Identification & Values \\
\hline Mode I CZ Toughness & $G_{I}\left(\mathrm{~J} / \mathrm{mm}^{2}\right)$ & $0.282(0.045)$ \\
Mode II CZ Toughness & $G_{I I}\left(\mathrm{~J} / \mathrm{mm}^{2}\right)$ & $0.782(0.087)$ \\
Friction Coef. & $\mu$ & $0.45 \pm 0.25$ \\
Mode I CZ Peak Traction & $\sigma_{0}(\mathrm{MPa})$ & $10 \pm 1.0$ \\
Mode II CZ Peak Traction & $\tau_{0}(\mathrm{MPa})$ & $32.4 \pm 7.4$ \\
\hline
\end{tabular}


Table 5: CFRP input material properties for scoping

\begin{tabular}{|l|l|l|}
\hline Description & Identification & Values \\
\hline Mode I CZ Matrix Toughness & $G_{I C m}\left(\mathrm{~J} / \mathrm{mm}^{2}\right)$ & 0.173 \\
Mode I CZ Fiber Toughness & $G_{I C f}\left(\mathrm{~J} / \mathrm{mm}^{2}\right)$ & 0.0870 \\
Mode II CZ Matrix Toughness & $G_{I I C m}\left(\mathrm{~J} / \mathrm{mm}^{2}\right)$ & 0.782 \\
Mode II CZ Fiber Toughness & $G_{I I C f}\left(\mathrm{~J} / \mathrm{mm}^{2}\right)$ & 0.392 \\
Mode I CZ Rate Coef. & $C_{R I}$ & 0.06 \\
Mode II CZ Rate Coef. & $C_{R I I}$ & 0.06 \\
Out-of-plane shear Rate Coef. & $C_{R 23,13}$ & 0.06 \\
\hline
\end{tabular}


Table 6: Energy absorbed predictions for scoping exercise

\begin{tabular}{|l|l|}
\hline Model Designation & Energy Absorbed (J) \\
\hline Model $A$ & 20.7 \\
Model B & 22.7 \\
Model $C$ & 26.6 \\
Model D & 23.4 \\
Model $E$ & 21.2 \\
\hline
\end{tabular}




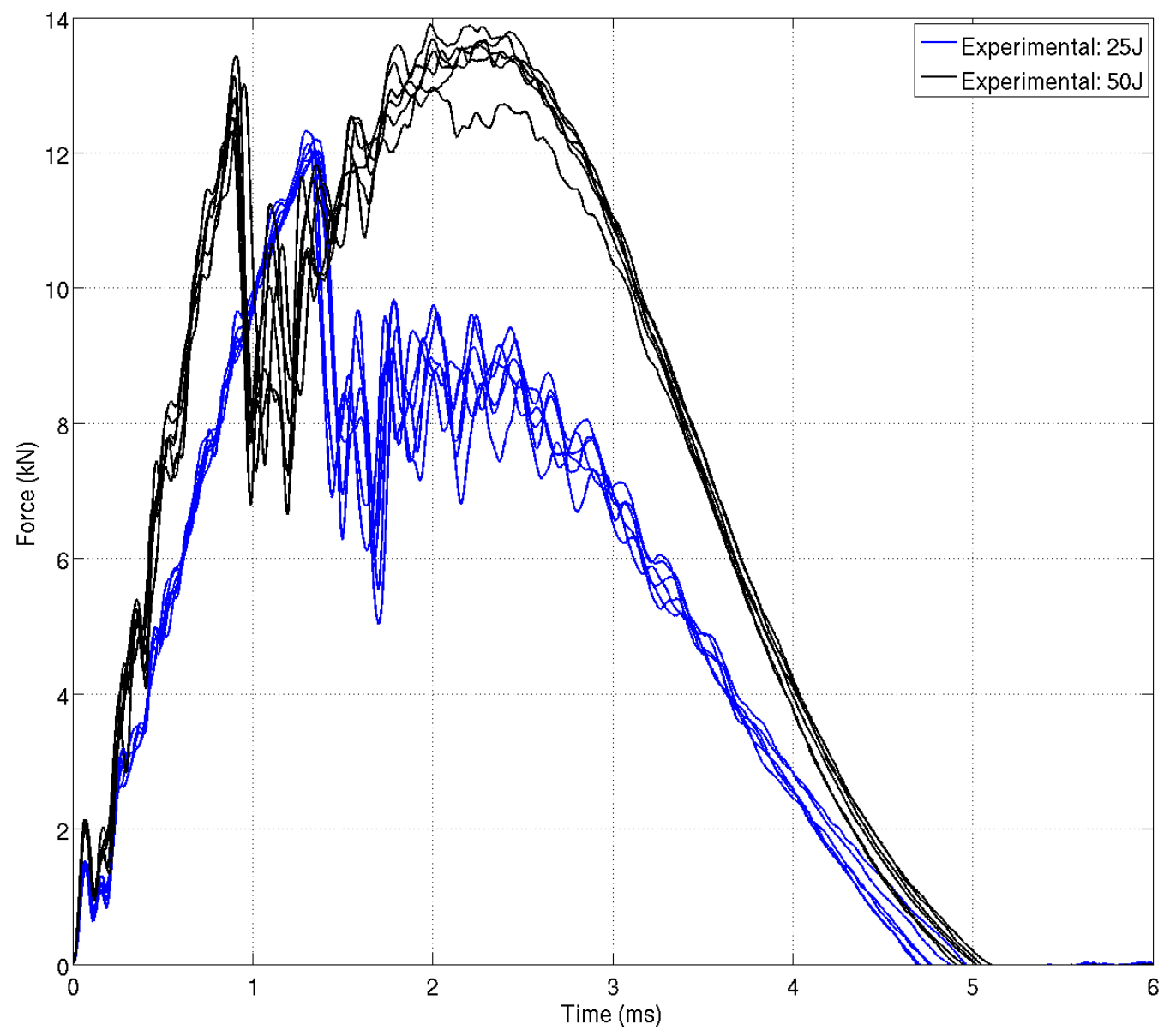

Figure 1 


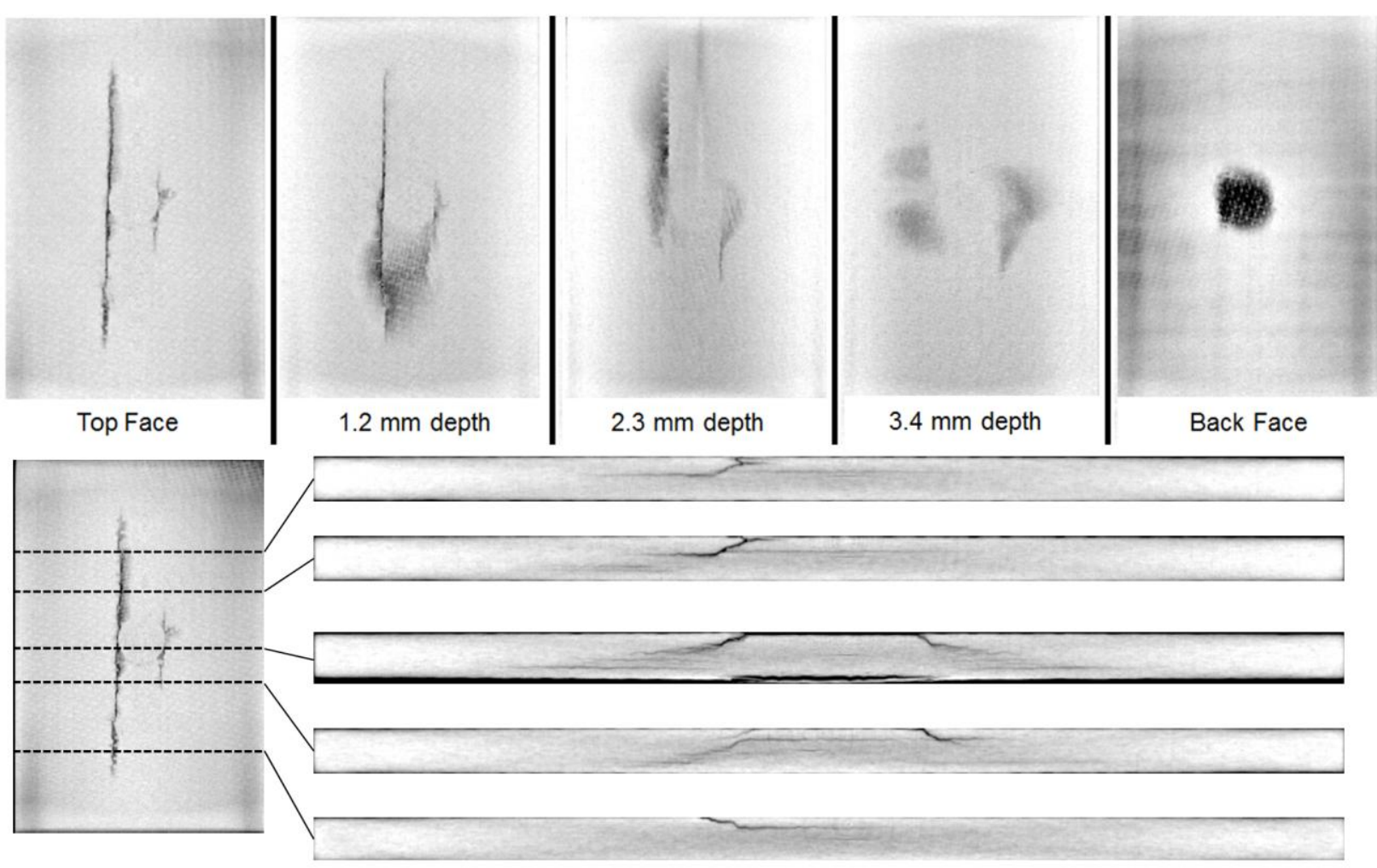

Figure 2 


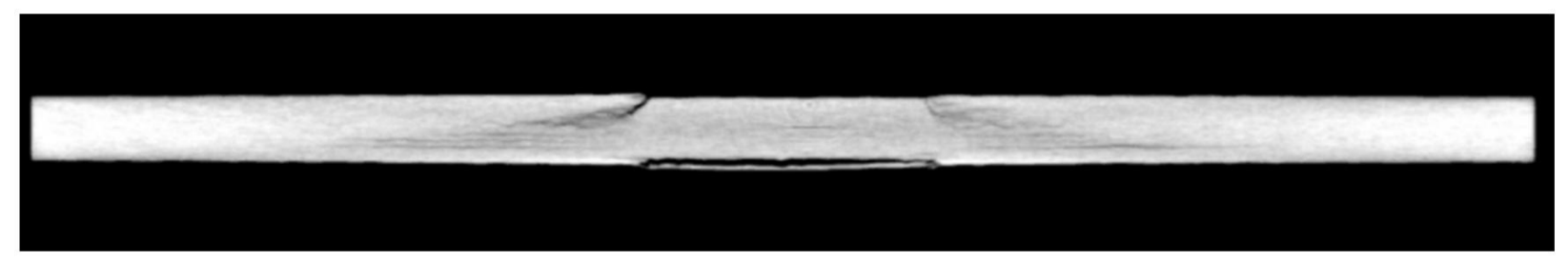

Figure 3a 


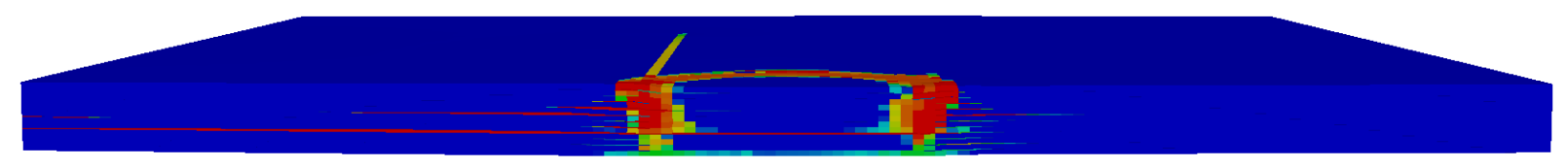

Figure 3b 

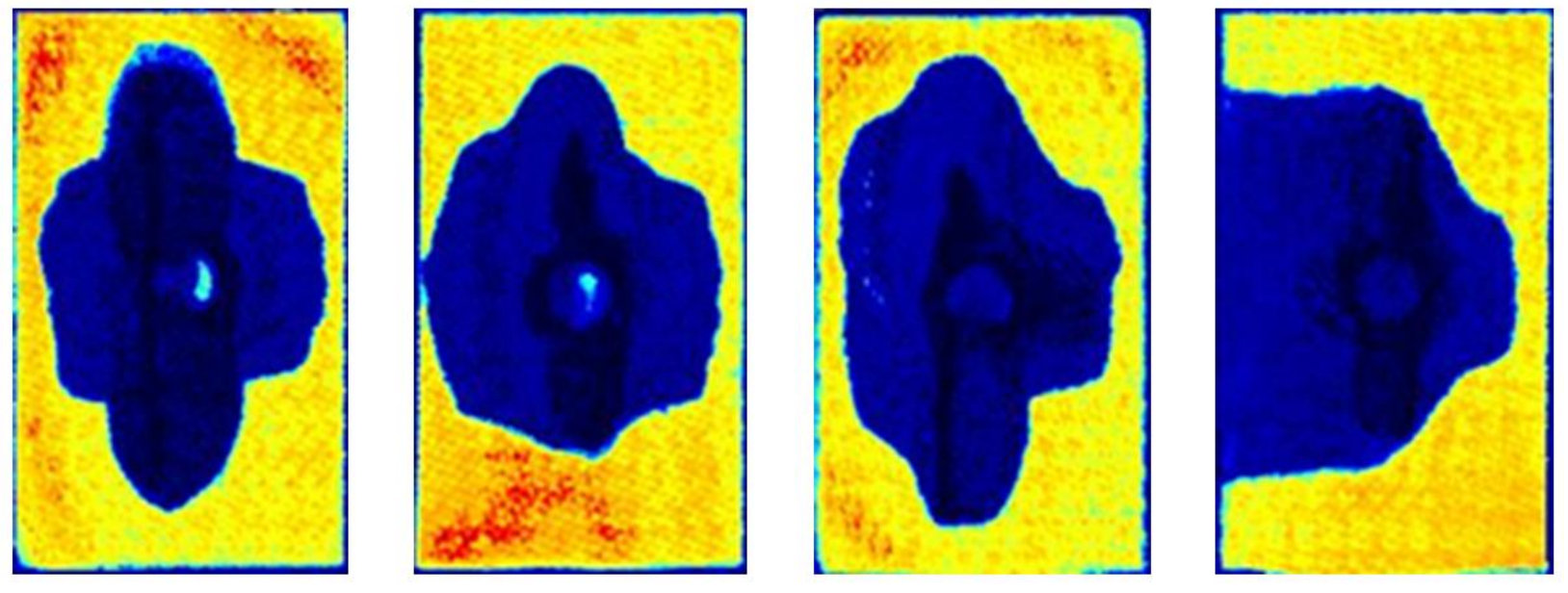

Figure 4a 

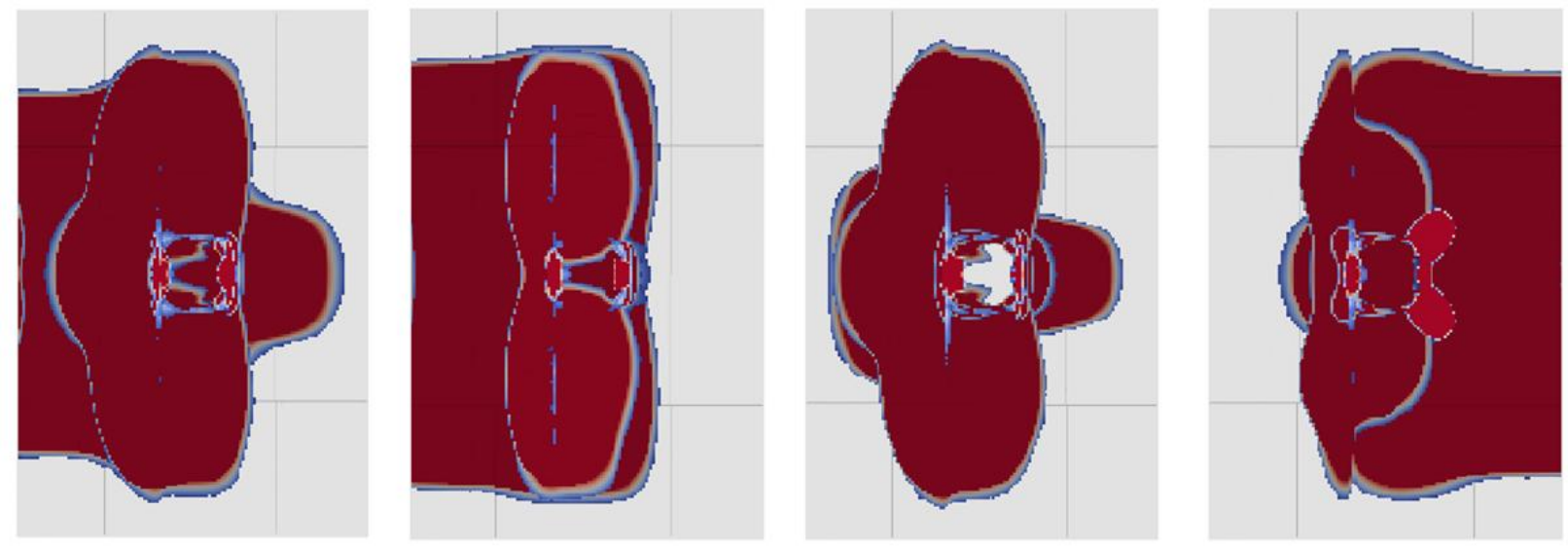

Figure 4b 


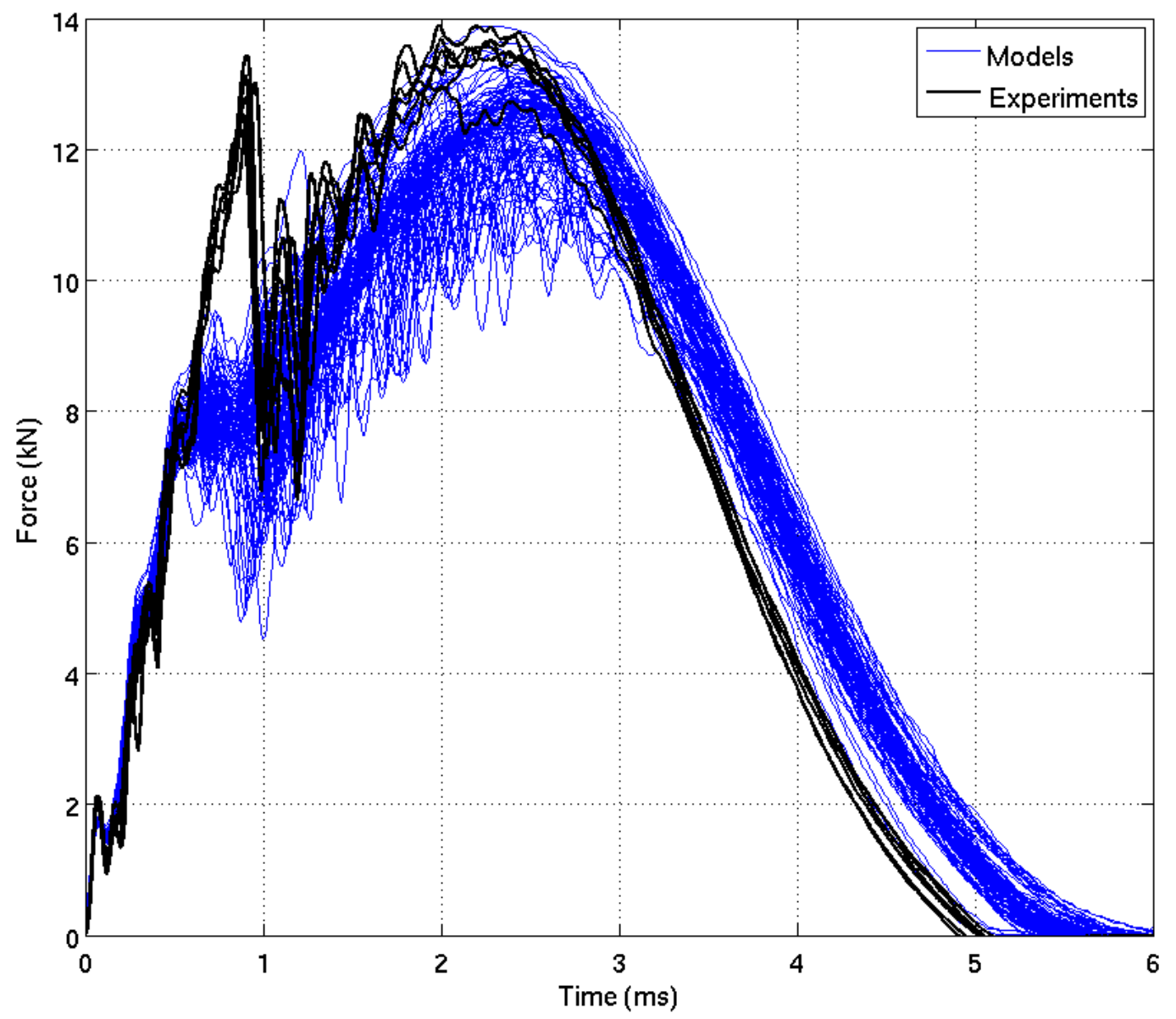

Figure 5 


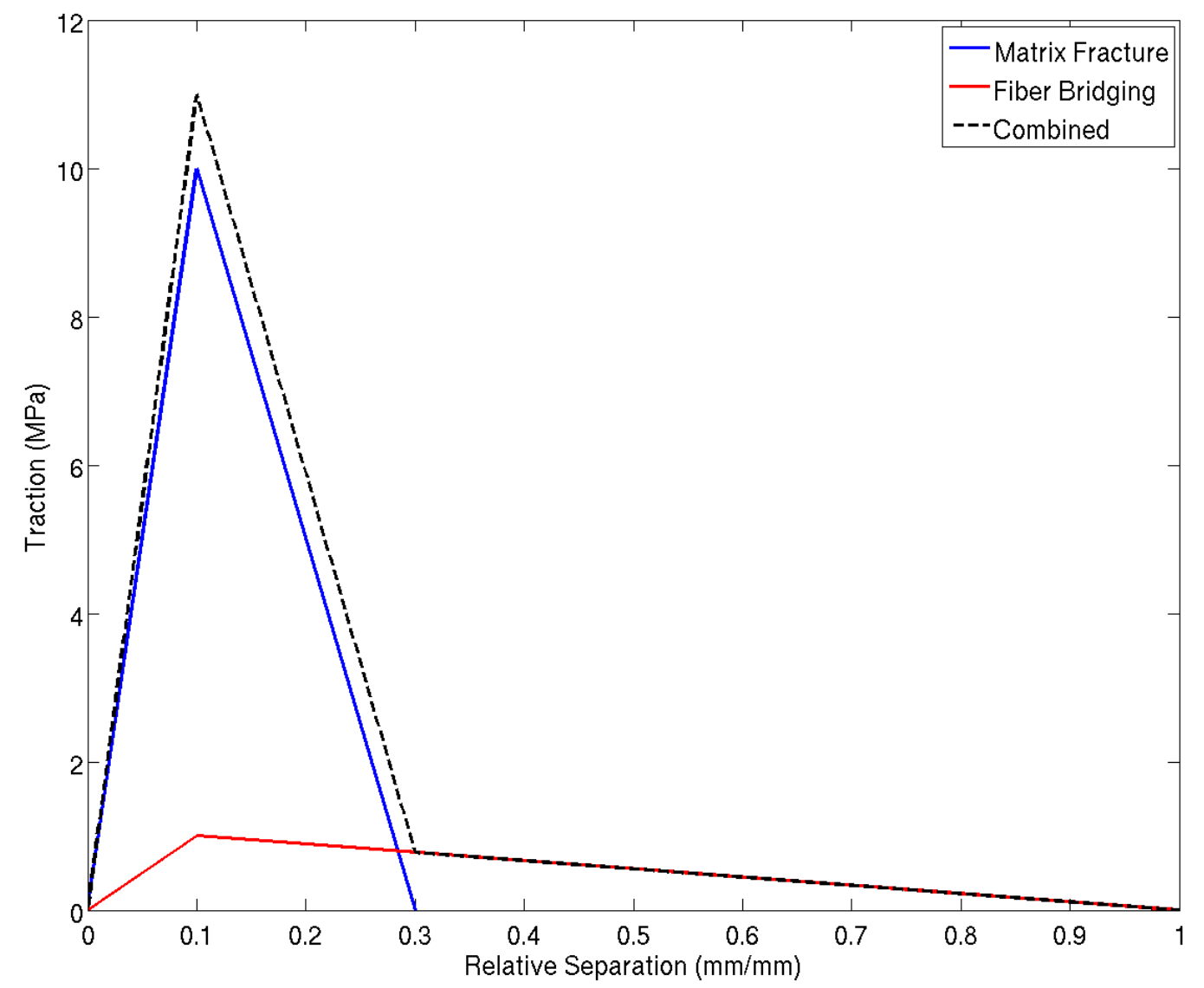

Figure 6 


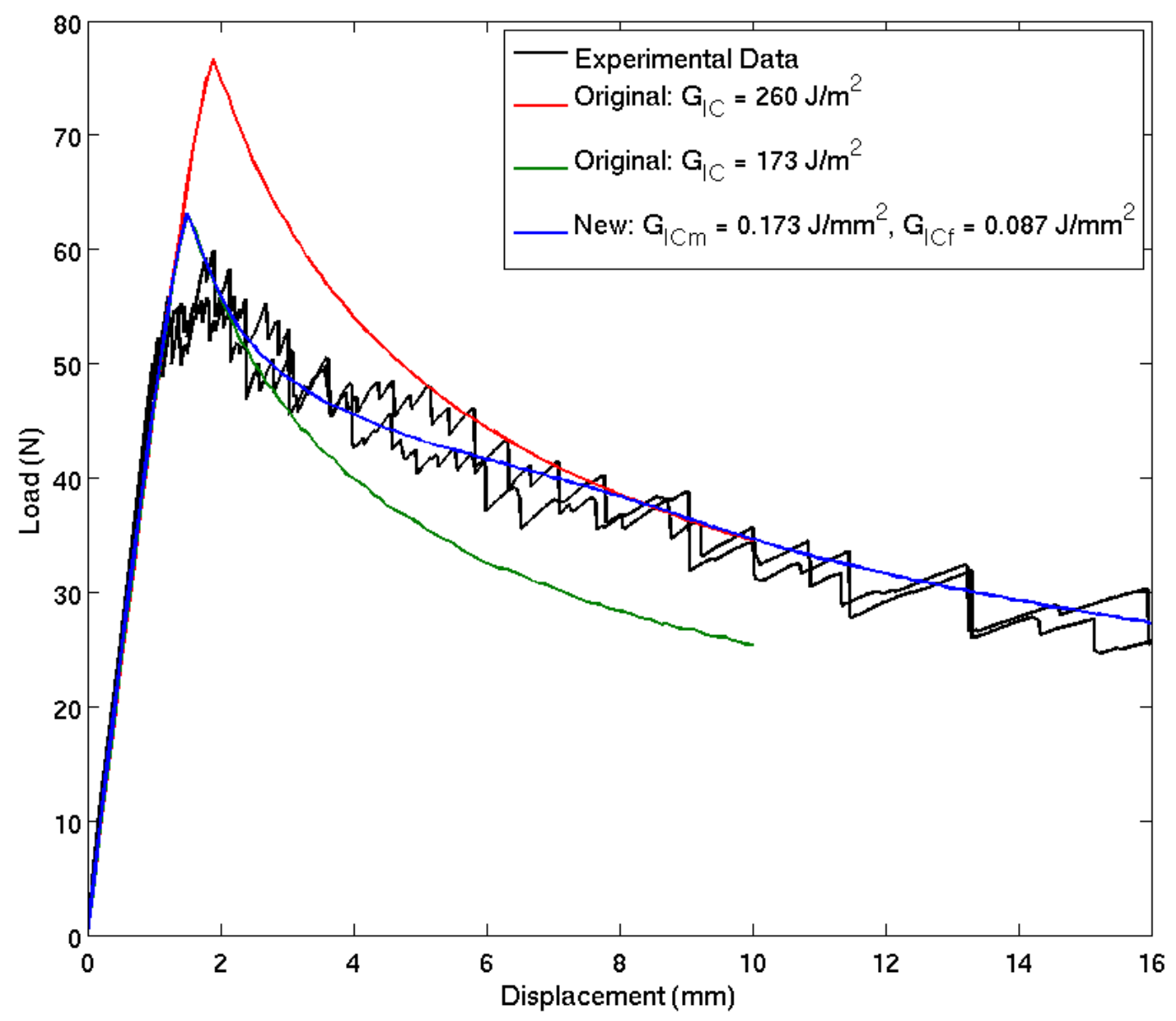

Figure 7 


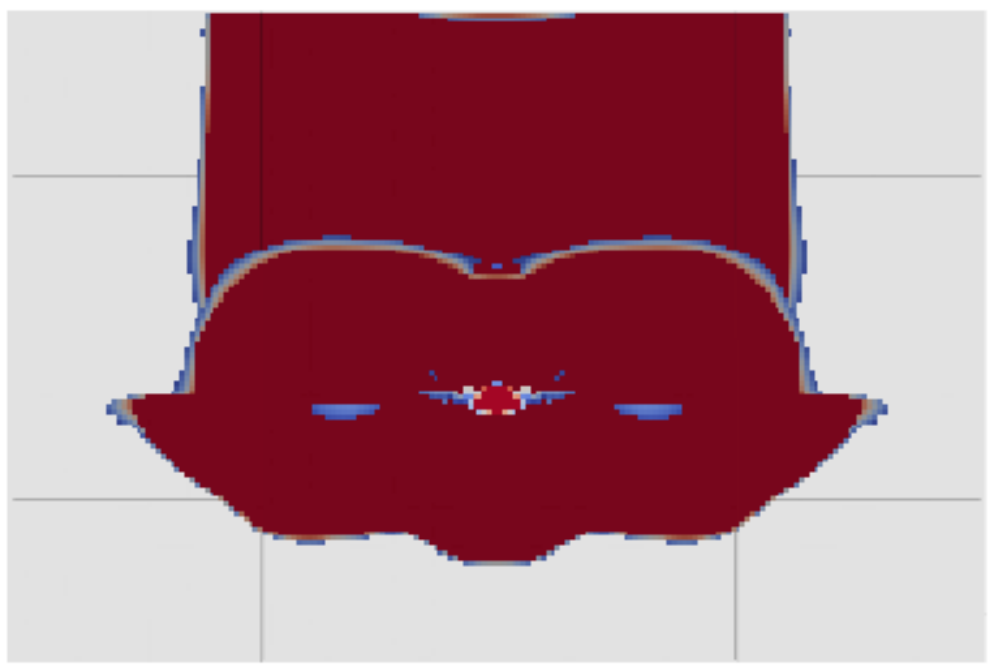

Figure 8a 


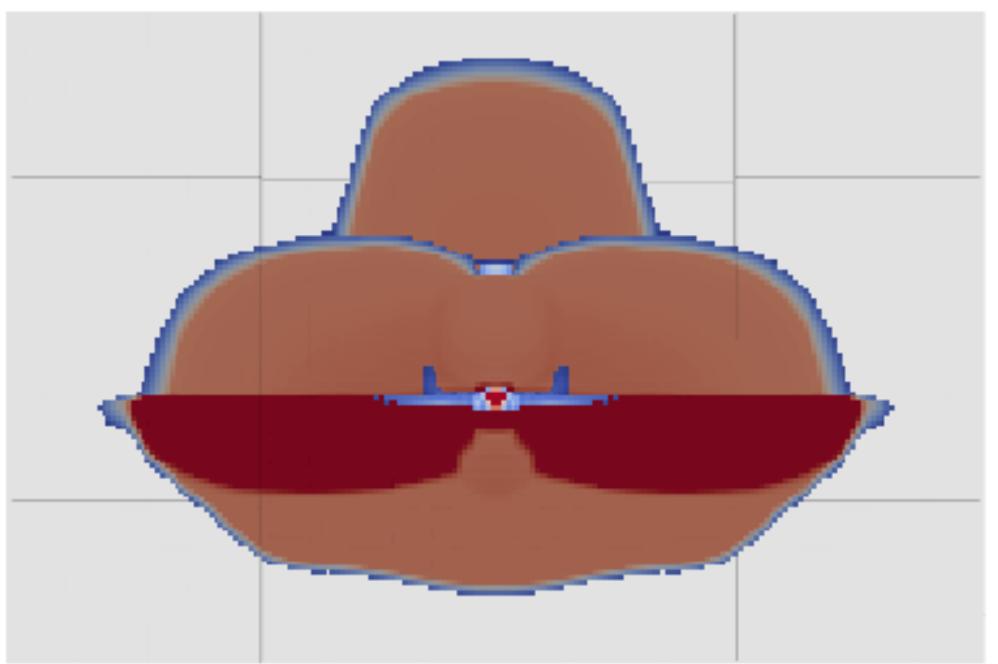

Figure 8b 


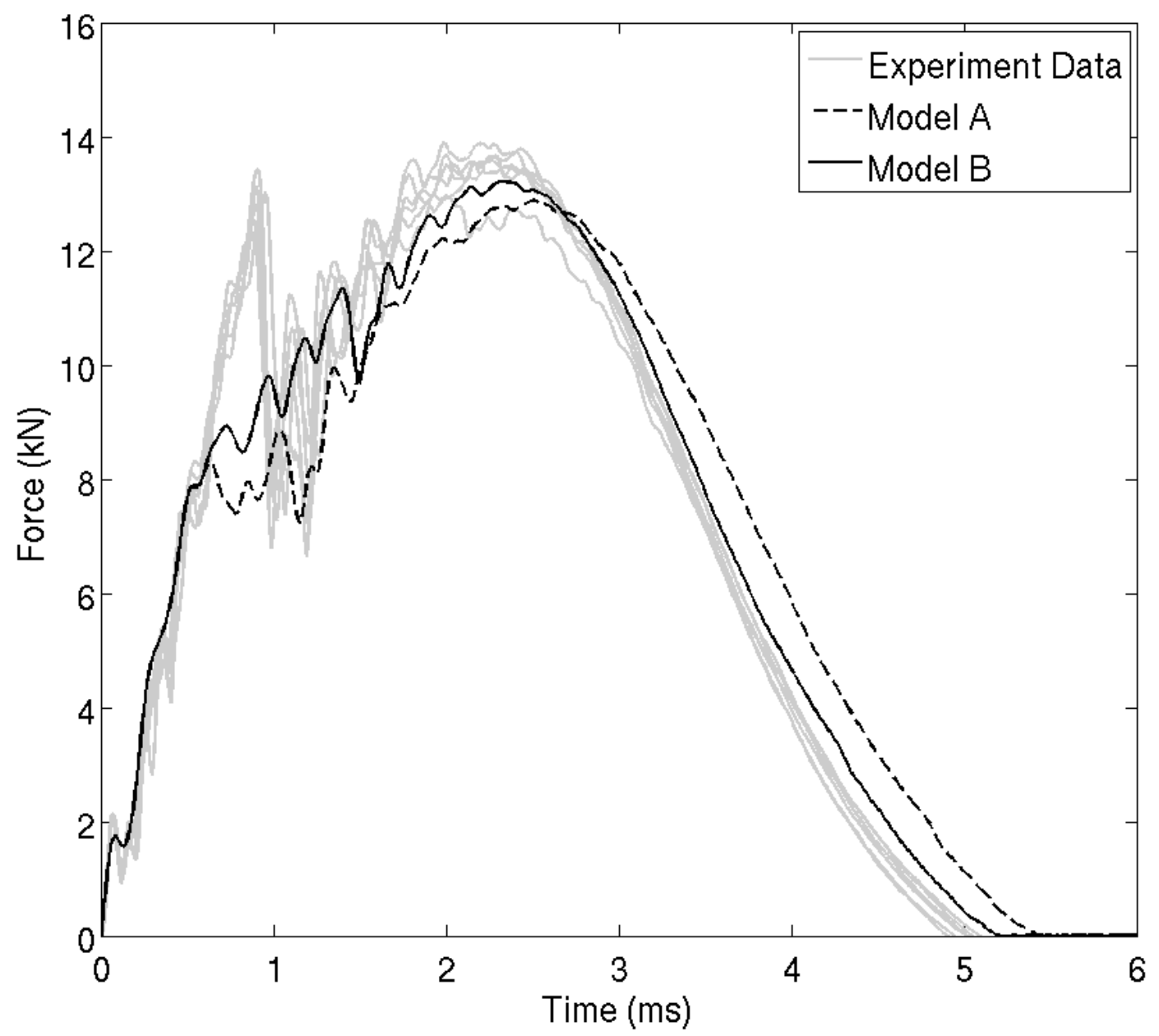

Figure 9a 


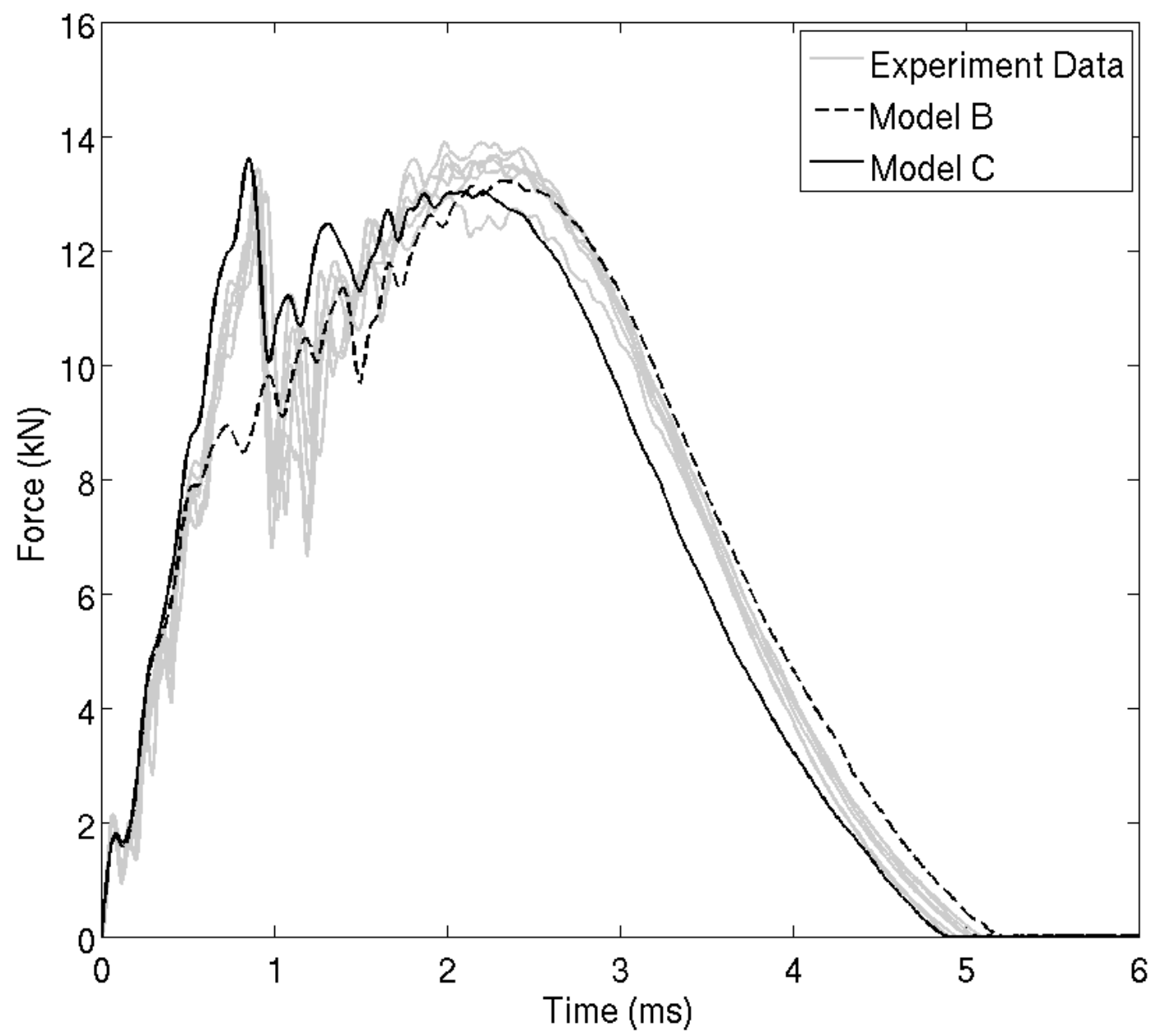

Figure 9b 


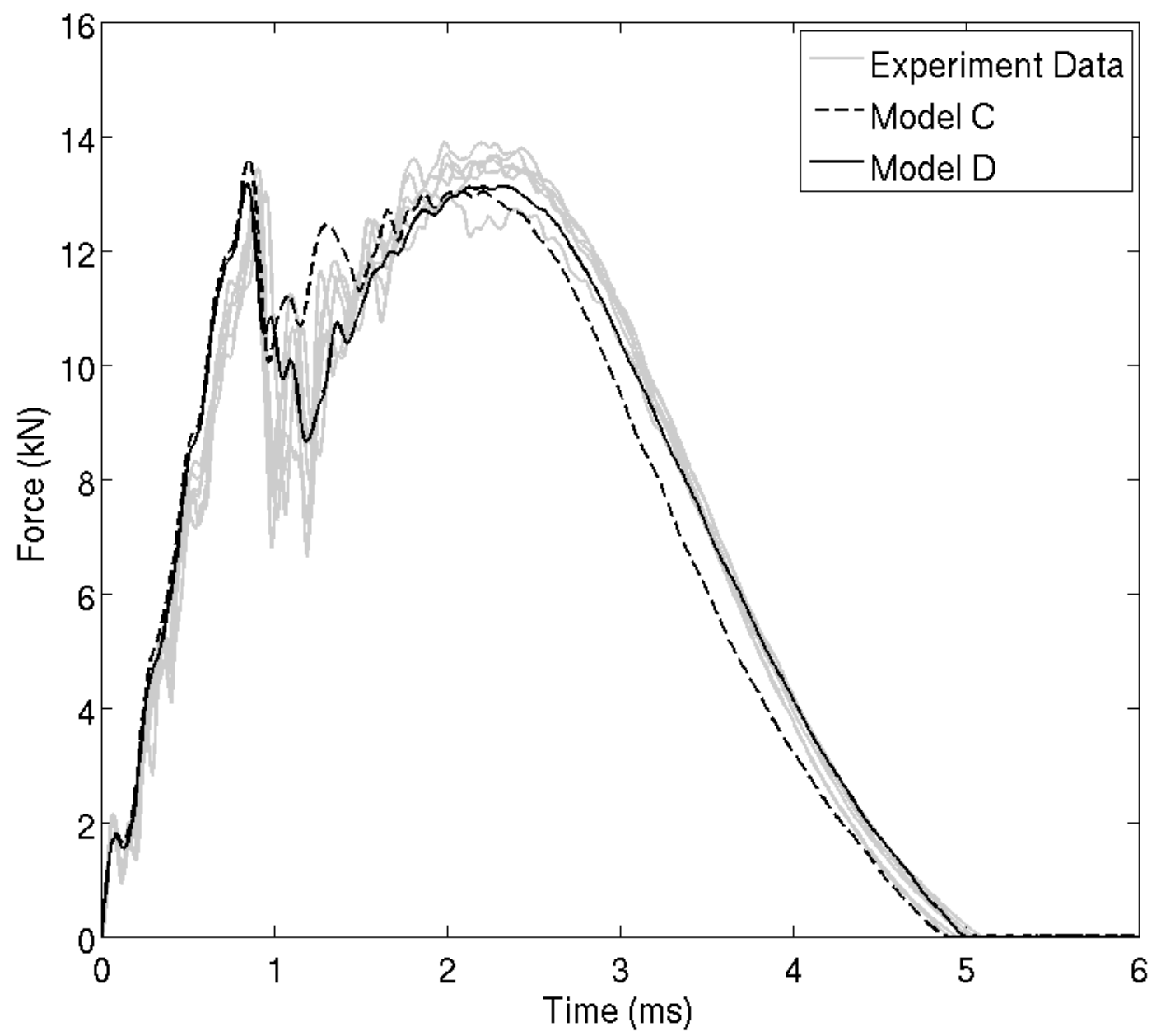

Figure 9c 


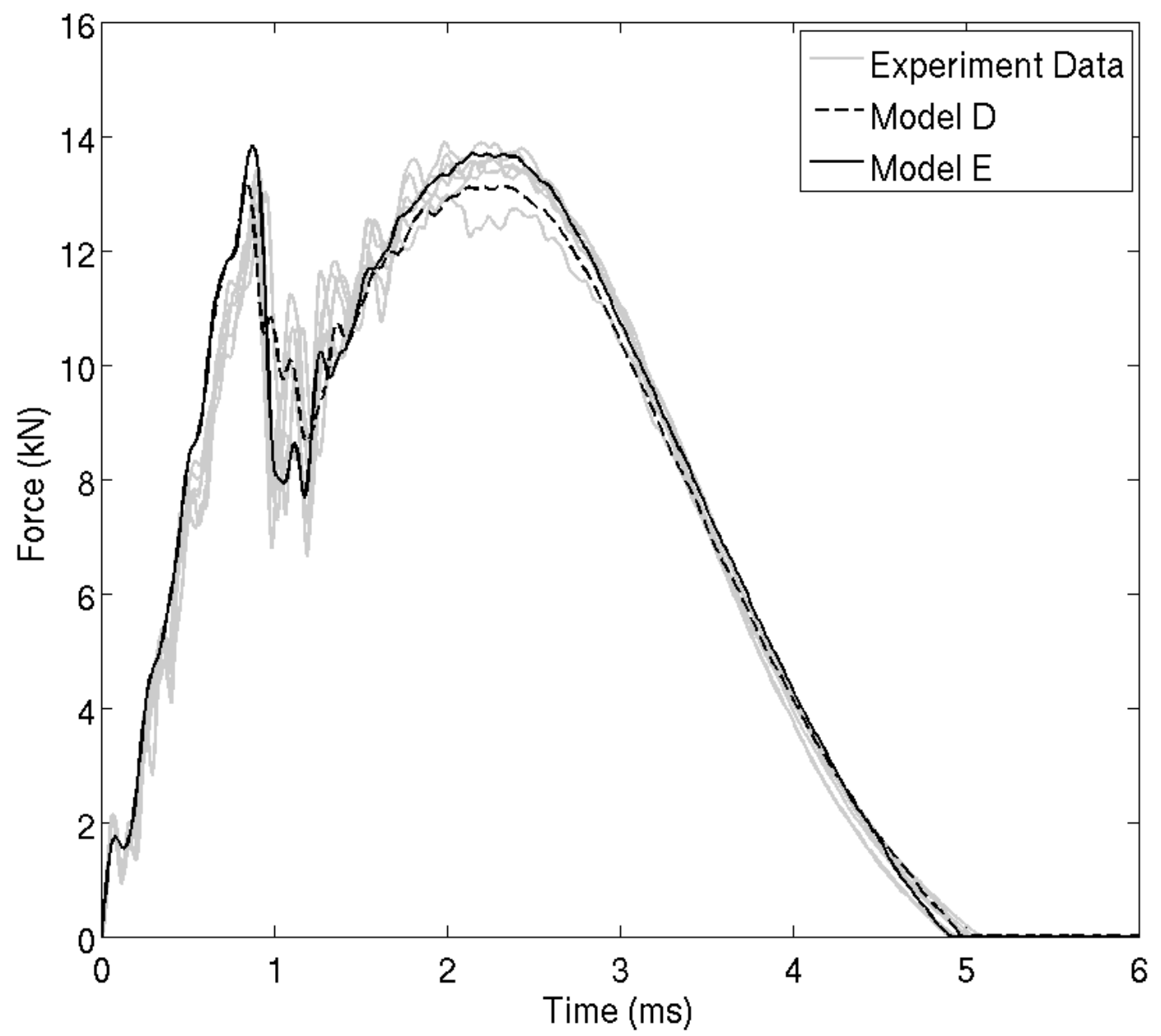

Figure 9d 


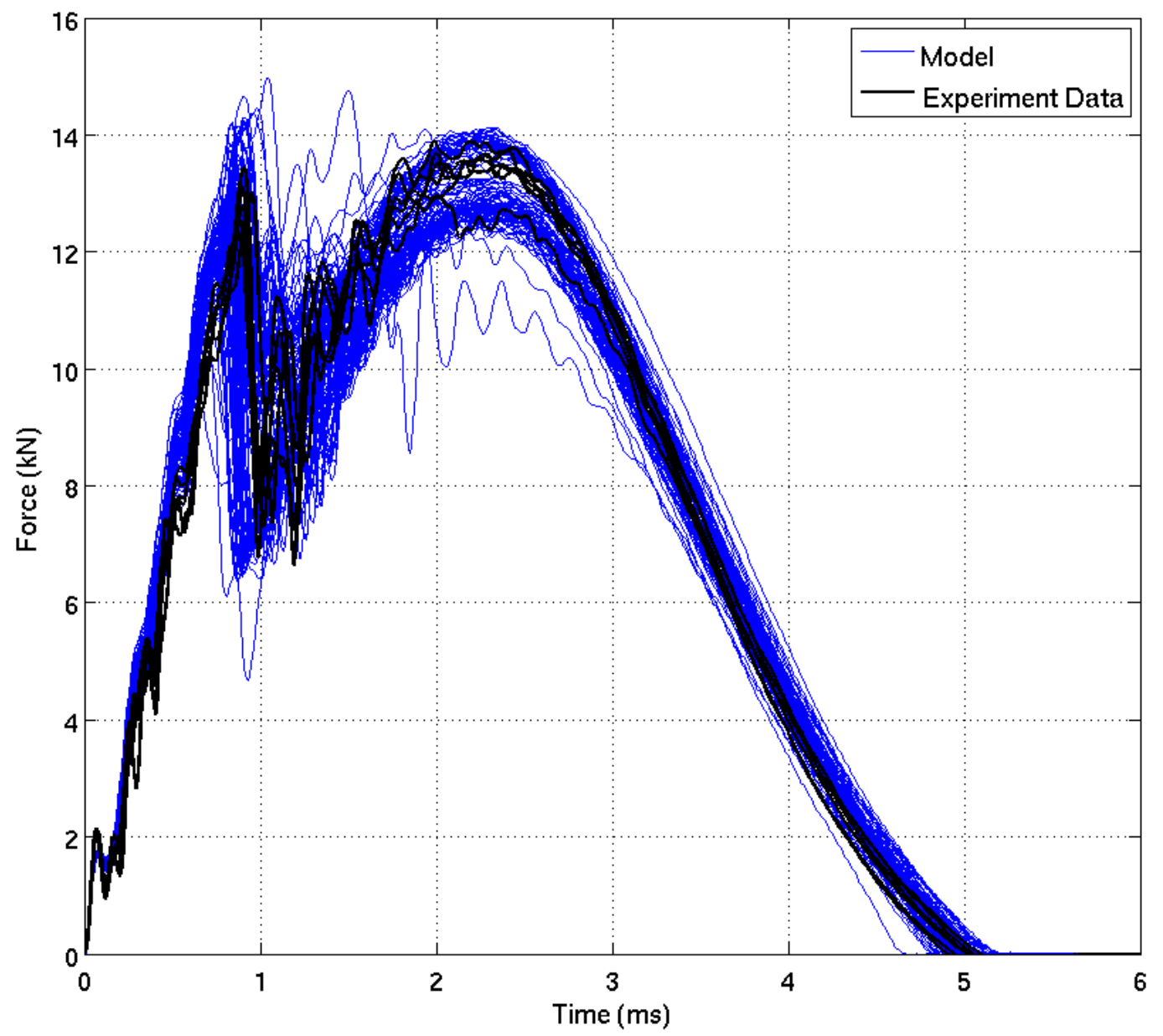

Figure 10 


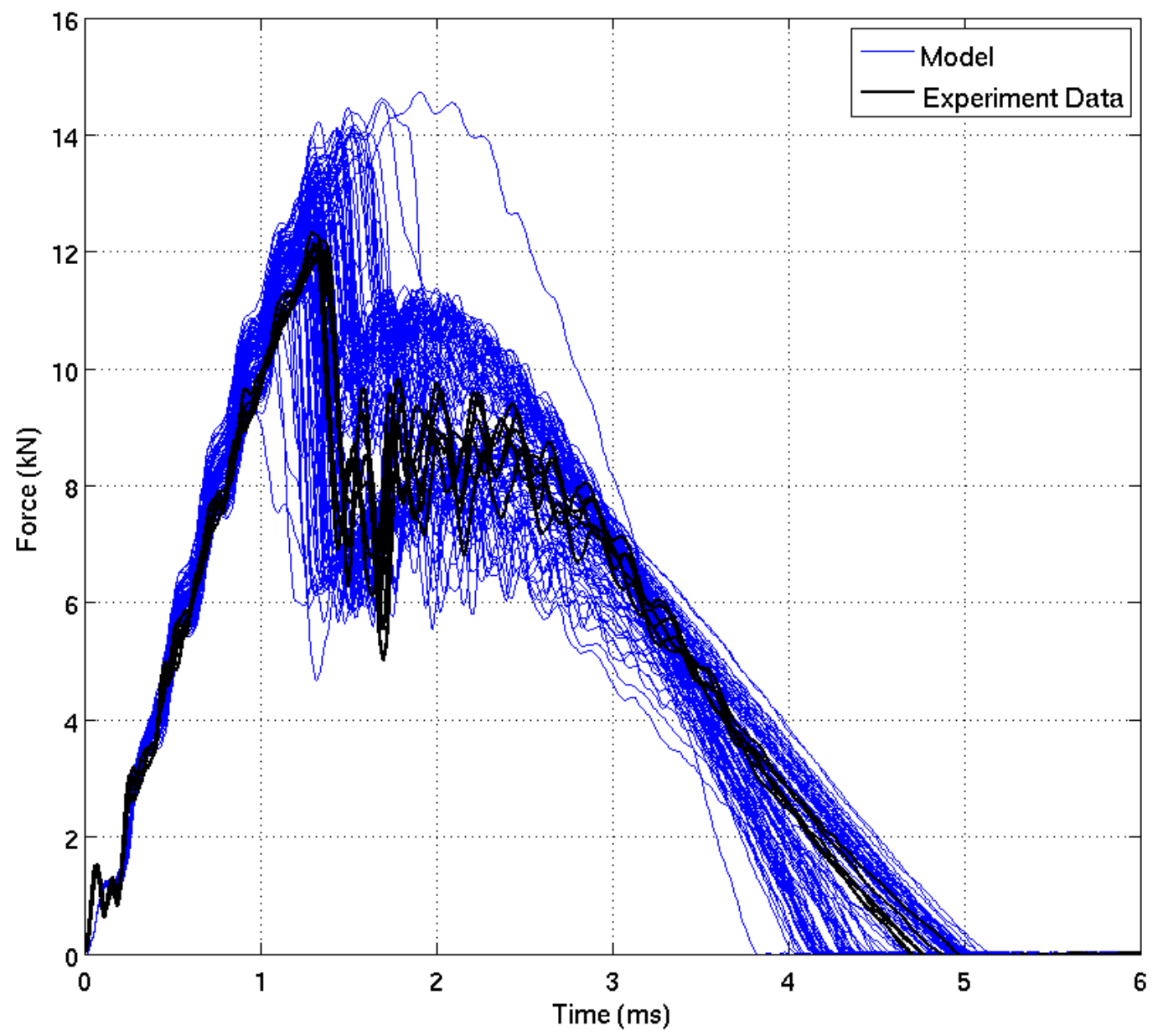

Figure 11 

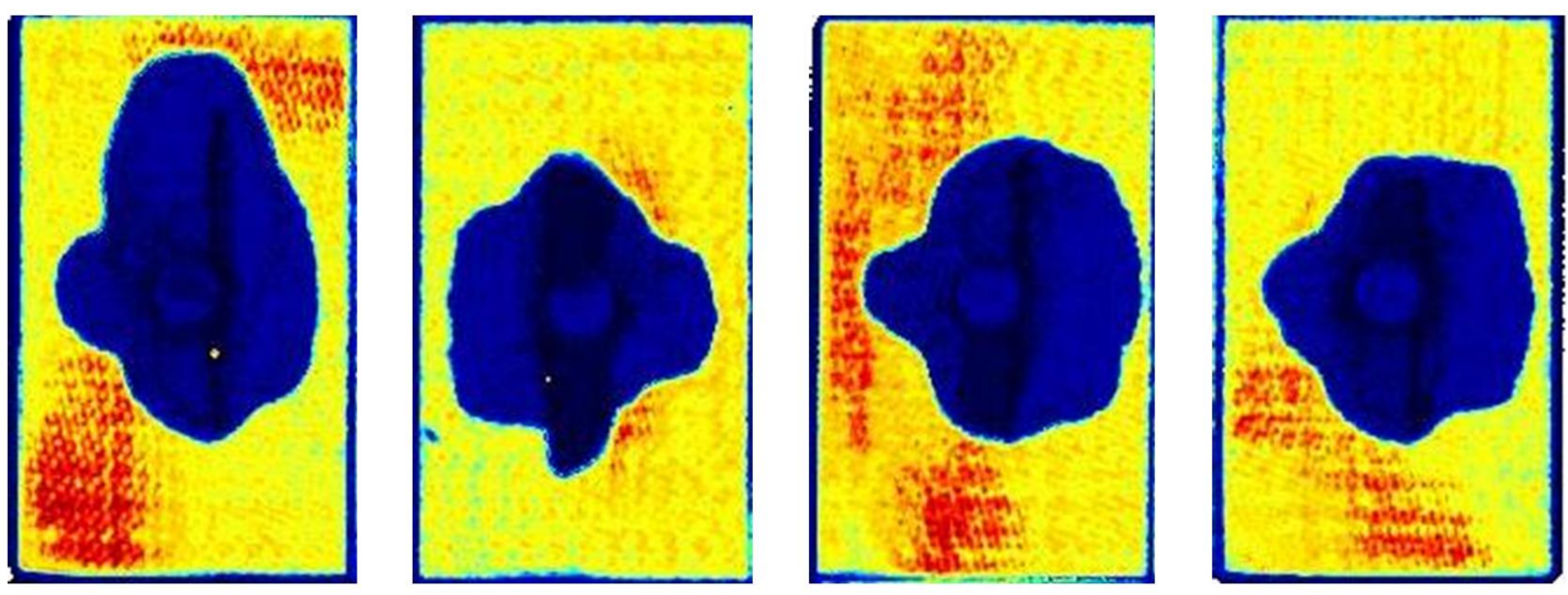

Figure 12a 

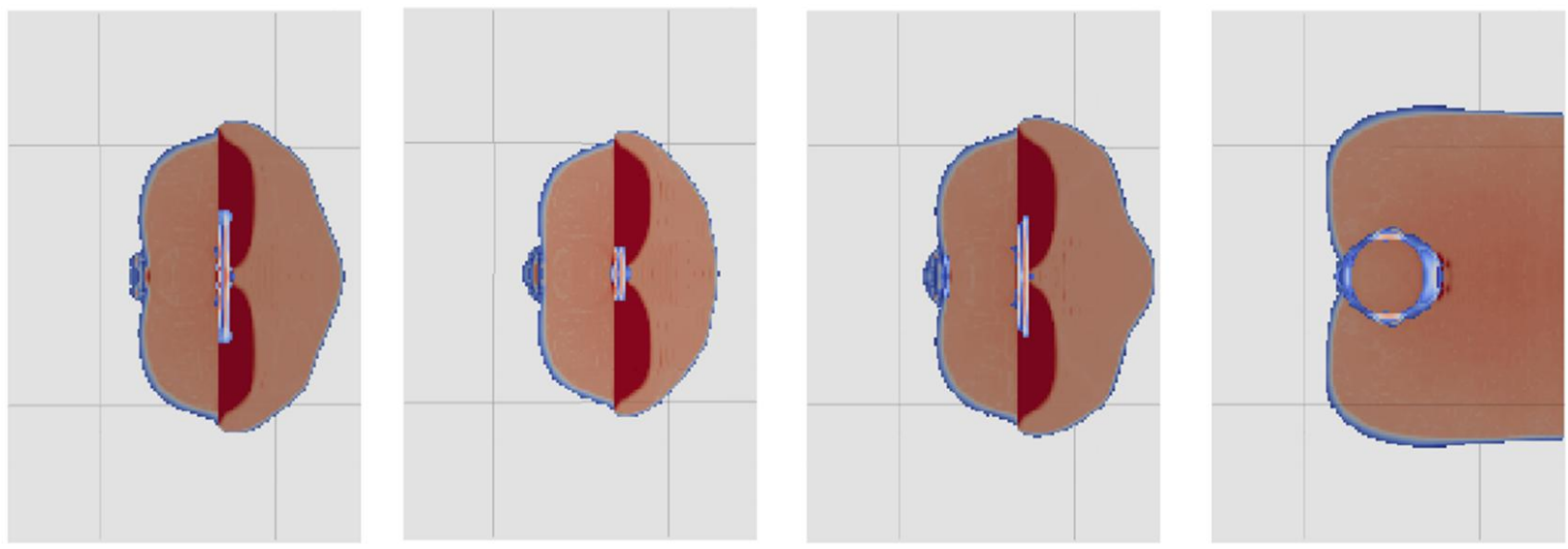

Figure 12b 